\title{
Los huertos urbanos como estrategia de transición urbana hacia la sostenibilidad en la ciudad de Málaga
}

Urban gardens as an urban transition strategy

for the sustainability in the city of Málaga

\author{
Remedios Larrubia Vargas \\ rlarrubia@uma.es \\ Juan José Natera Rivas \\ jinatera@uma.es

\section{David Carruana Herrera} \\ carruanadavid@gmail.com \\ Departamento de Geografía \\ Universidad de Málaga (España)
}

\section{Resumen}

La agricultura urbana es un fenómeno emergente desde hace varias décadas. Es una actividad que aporta nuevos significados a la práctica agrícola, más allá del aspecto productivo, dotándola de una función social para distintos grupos de población. Al mismo tiempo también resulta una oportunidad de recuperación de espacios abandonados, dotándoles de nueva identidad en la ciudad. En este contexto, la presente investigación se enmarca en la ciudad de Málaga donde se ha inventariado 19 huertos urbanos, promovidos tanto por organismos públicos como privados. Su análisis se ha basado en una red de entrevistas realizadas a los promotores de estos huertos a fin de subrayar sus rasgos más sobresalientes en cuanto a funcionamiento, características socioeconómicas de los usuarios, gestión, motivaciones y tipología existente. Los resultados 
ponen de manifiesto no sólo la diversidad de proyectos existentes sino también los beneficios que aportan al desarrollo personal de los usuarios, a la economía familiar y al entorno urbano.

Palabras claves: huerto urbano; sostenibilidad; cultivos hortícolas; proyecto comunitario.

\begin{abstract}
Urban agriculture has been an emerging phenomenon for several decades, and it has contributed new meanings to agricultural practice, beyond the productive one, it has endowed it a social function aimed to different population groups. And it can be seen as an opportunity to recover abandoned spaces, giving them a new identity in the city. In Malaga city 19 urban gardens have been inventoried, promoted by both public and private organizations. The aim of this paper is to analyze them: information, both cuantitative and cualitative, has been obtained from interviews with promoters of these orchards in order to highlight their most outstanding features in terms of operation, socio-economic characteristics of the users, management, motivations and typology. Our findings show not only the diversity of existing projects, but also their benefits related with the personal development of users, the family economy and the urban environment.
\end{abstract}

Key words: urban garden; sustainability; horticultural crops; community project.

\title{
1 Introducción
}

Desde su inicio, la ciudad ha estado estrechamente relacionada con la agricultura. La presencia de casas con huertos urbanos era frecuente en la ciudad precapitalista; sin embargo, el proceso de industrialización impuso la ruptura de la ciudad organicista donde se combinaban usos en el suelo urbano y se mantenía una cierta continuidad e integración con los ecosistemas próximos. La orientación al mercado, con fines meramente especulativo, impuso un desarrollo urbano guiado por la especialización del suelo y la ruptura con el entorno físico; de esta forma, los espacios agrícolas desaparecen en las tramas urbanas consolidadas y se limitan a las áreas periurbanas, mientras que los espacios rurales se especializan en la producción de alimentos que se destinan al consumo concentrado de los espacios urbanos.

El crecimiento urbano, donde la agricultura ha permanecido al margen de las consideraciones de los diseños urbanísticos, ha llevado recientemente que desde el ámbito del urbanismo, la arquitectura, la ingeniería, etc. se muestre interés por integrar la agricultura en la planificación 
urbanística, incluyendo la agricultura urbana como propuesta para la sostenibilidad urbana (Soler \& Rivera, 2014).

En esta línea, la sostenibilidad de las ciudades es fundamental para el aprovechamiento eficaz de los recursos europeos, que es un objetivo importante de la estrategia Europa 2020 y la agenda 2030 para el desarrollo sostenible.

La integración política en diferentes escalas territoriales (internacional, europea, local) y las nuevas formas de gobernanza son claves para aprovechar al máximo todo lo bueno que puede ofrecer la urbanización. Iniciativas de la Comisión Europea (Premio Capital Verde Europeo, Pacto de los Alcaldes) por las que las ciudades cooperan voluntariamente con la UE, o a nivel internacional (Pacto de Milán), cuyo objetivo principal es introducir la alimentación en las agendas políticas de las ciudades, así como todas las políticas orientadas hacia las ciudades que conforman la denominada "Agenda Política Europea", son claros ejemplos del esfuerzo por involucrar a las autoridades municipales en el diseño de las políticas urbanas-verdes a nivel europeo.

En este contexto la agricultura urbana surge como una clara estrategia de regeneración urbana de espacios degradados, como espacios de socialización, inserción social, de ocio, ocupacional, en combinación con la producción de alimentos sanos y sostenibles. Como indica Soler (2009), en la actualidad dos procesos simultáneos y contradictorios se desarrollan en relación a la agricultura: uno la pérdida continuada de suelos fértiles en la periferia de las ciudades de la mano de la expansión urbana planificada; otro, se consolida la recuperación y creación de huertas dentro de la trama urbana.

La agricultura urbana aparte de fomentar hábitos alimenticios más saludables, producir las propias hortalizas a un coste inferior al del mercado, supone además una nueva forma de entender, valorar y respetar la naturaleza, de aumentar las zonas verdes en las ciudades y reducir la huella de carbono. De esta forma, la cultura de los huertos urbanos se ha ido extendiendo a lo largo de los años, tanto en los países desarrollados como en desarrollo.

\section{Objetivo, fuente y metodología}

En las últimas décadas y, especialmente, a partir de la última crisis económica de 2008 que tuvo su principal desencadenante con el estallido de la burbuja inmobiliaria, la ciudad representa un contexto privilegiado a la hora de intervenir y experimentar soluciones en momentos de grandes transformaciones cuando las respuestas clásicas y convencionales no parecen conseguir 
resultados. La agricultura urbana se ha desarrollado en todo el mundo como una de las prácticas más factibles de transformación territorial, económica y social. En todos los continentes, las experiencias son diversas y numerosas, constituyéndose este tipo de agricultura como un fenómeno complejo y heterogéneo, capaz de adaptarse a las más diversas situaciones y experiencias.

A partir de esta evidencia, el presente trabajo analiza una de las prácticas alternativas más interesantes en los últimos años llevadas a cabo en las ciudades, esto es, la agricultura urbana, que se ha convertido en uno de los elementos característicos de la nueva realidad alimentaria, una práctica económica alternativa que se está desarrollando con fuerza en las últimas décadas en el continente europeo y, que ha llegado, de forma más tardía, a nuestro país.

La presente investigación parte de una hipótesis general al hilo de la revisión bibliográfica, por un lado que la agricultura urbana es un elemento de transformación territorial, ambiental y socioeconómica en las ciudades y, por otro lado, que cada experiencia responde y se adapta a las distintas realidades y colectivos de las ciudades.

De este modo, surge el objetivo específico de la investigación, demostrar y describir el carácter multidimensional y polifuncional que tiene la agricultura urbana en la ciudad de Málaga a través de la identificación y análisis de las distintas experiencias existentes capaces de adaptarse a diferentes realidades socioeconómicas y ambiental. Para ello, se analiza cuáles son los motivos que favorecen el desarrollo y creación de los huertos urbanos en la ciudad, caracterizando la situación actual de los mismos, estableciendo su tipología y determinando las características esenciales de funcionamiento, el perfil social de los usuarios y su proyección futura.

De acuerdo con los objetivos, la metodología seguida para llevar a cabo la presente investigación ha sido básicamente de tipo cualitativo. La primera fase se ha centrado en la búsqueda y recopilación de diferentes fuentes de información, tanto trabajos de investigación como documentos oficiales, publicaciones institucionales y material multimedia. La segunda fase fue la contabilización y localización de los huertos existentes en la ciudad, una realidad muy cambiante, poco estructurada y catalogada, a pesar de la existencia actual de la Red de Huertos Urbanos de Málaga. Para su inventarización se partió de dos trabajos previos, el realizado por Fernández (2012) desde el ayuntamiento de Málaga que impulsó los cuatro primeros huertos urbanos en la ciudad y el inventario desarrollado por el área de innovación y digitalización urbana del Ayuntamiento de Málaga, dicha información se completó con la obtenida a través de 
las redes telemáticas, de las noticias en los medios de comunicación y con la observación directa de la ciudad por parte de los autores del trabajo.

La parte esencial de la investigación ha sido el trabajo de campo. Concretamente se ha recurrido a las entrevistas semiestructuradas en las que el entrevistador despliega una estrategia mixta, alternado preguntas estructuradas y preguntas espontáneas. Ello permite obtener datos sistemáticos y además conocer las motivaciones y otros aspectos que sólo aparecen cuando la persona se expresa libremente. El grueso de entrevistas, 19 de ellas, se realizó a cada persona que estaba al frente de cada una de la entidad promotora de los huertos urbanos existentes en la ciudad, preferentemente a los los promotores y/o coordinadores de los mismos. Las entrevistas fueron realizadas durante la primavera y verano de 2018, completándose en la primera mitad de 2019 con los nuevos proyectos puestos en funcionamiento. Por ello, el grueso de la información que se plasma en esta investigación procede de la opinión de los coordinadores de los huertos que tienen un conocimiento pormenorizado de los huertos y sus usuarios, y les permiten dar una respuesta aproximada de los rangos de edades, formación, situación laboral, etc. de los usuarios. Sin embargo, para perfilar aspectos relativos al funcionamiento de los huertos (inputs suministrados, labores de cultivo, experiencia personal, etc.) se realizaron 8 entrevistas individuales a los usuarios de las parcelas. Los participantes eran localizados vía telefónica o mediante correo electrónico. Todas las entrevistas se realizaron presencialmente en el huerto, haciendo coincidir las entrevistas con momentos de actividad en los huertos para así poder observar directamente el funcionamiento de los mismos. Finalmente se realizó una entrevista vía telefónica a la Gerencia de Urbanismo del Ayuntamiento de Málaga, que impulso el desarrollo de los huertos en la ciudad.

El formulario se estructuró en 4 bloques. En el primero se atendía a cuestiones de constitución y gestión de los huertos (año, motivación, promotor, etc.); en el segundo se indagaba sobre el perfil social de los usuarios (edad, sexo, estudios, formación en agricultura, lugar de residencia, situación laboral, renta, etc.); en el tercero se obtenía información acerca del perfil técnico del huerto (localización, superficie cultivable, número de parcelas, tamaño, infraestructuras, presupuesto, etc.), y por último se preguntó sobre el manejo del huerto (especies cultivadas, cosechas, insumos, tareas culturales, trabajo aplicado, productividad, problemas de cultivo, etc.) (la guía de la entrevista aparece recogida en el Anexo I).

La organización de la información nos ha permitido estructurar el trabajo en las siguientes partes: tras la introducción, los objetivos y la metodología, se expone el estado de la cuestión de la 
agricultura urbana, atendiendo a los hechos históricos más relevantes en su evolución y a la definición y delimitación de términos que a menudo se usan indistintamente (agricultura urbana y periurbana) cuando aluden a realidades diferentes. Seguidamente se da cuenta sobre la tradición de la huerta urbana en la ciudad de Málaga, así como su renacer actual en la ciudad. En el siguiente epígrafe se desarrolla el grueso del trabajo, un análisis detallado de todos los huertos urbanos inventariados en la ciudad, para terminar con las conclusiones.

\section{Estado de la cuestión}

\subsection{Hitos fundamentales del proceso histórico de los huertos urbanos}

A pesar del protagonismo actual de la agricultura urbana, hay que señalar que es una realidad que tiene una larga trayectoria histórica. Los huertos urbanos tradicionalmente han formado parte del proceso de constitución de las ciudades siempre bajo una perspectiva funcional dirigida hacia la productividad y la subsistencia. Sin embargo, la significación que demuestra este fenómeno en la actualidad contrasta con su carácter histórico. Hoy en día es posible descubrir múltiples iniciativas de agricultura urbana que responden a unos principios que se alejan de la producción exclusiva de alimentos. De esta forma los huertos urbanos han ido respondiendo y adaptándose a las distintas necesidades de los habitantes de la ciudad ${ }^{1}$.

A lo largo de la historia ha existido en la ciudad un estrecho vínculo entre espacios verdes y agricultura. Fue precisamente con la Revolución Industrial cuando desaparece por completo esta interrelación (Arosemena, 2012). En estos momentos una serie de circunstancias reactiva la necesidad de recurrir al huerto urbano como herramienta de subsistencia en época de crisis, resurgen así en las ciudades del S. XIX los huertos urbanos para cumplir esta función bajo la denominación de "Huertos para pobres" ("Poor Gardens") (Villace et al., 2014).

A este proceso también se suman muchas ciudades de los Estados Unidos, donde los primeros huertos surgen concretamente en la ciudad de Detroit en 1894 (Lawson, 2004; Moran, 20082009) como respuesta a la depresión económica de 1880, son los denominados "Pingree Potato Parchs" ("Parcelas de patatas"), medida a la que se recurrirá posteriormente en la Gran Depresión de 1929 con los denominados "Relief Gardens" o "Huertos de emergencia" (Morán, 2010).

1 Un amplio desarrollo sobre el inicio y evolución de los huertos urbanos se puede encontrar en las siguientes referencias bibliográficas: Lawson, 2004; Morán, 2008-2009, 2010; Morán \& Hernández, 2011. 
Durante las dos grandes guerras, la agricultura urbana era casi una actividad obligada por los estados. En estos momentos los huertos urbanos fueron promovidos por las administraciones como una forma de asegurar el abastecimiento de las ciudades, serían los denominados "Huertos de guerra" ("War Gardens") (Arosemena, 2012).

Tras la II Guerra Mundial estas experiencias cayeron en el olvido y las ciudades europeas comenzaron una reconstrucción en las que no dejaron espacio para los huertos urbanos. Habrá que esperar hasta la década de los sesenta del S. XX para que vuelvan a resurgir, promovidos ahora por comunidades de la ciudad y grupos ecologistas, inherentes a las crisis energética y económica existentes. En estos huertos las ideas que subyacen son el desarrollo local, la integración social y la educación ambiental. Son los denominados "Huertos comunitarios" ("Community Gardens") que se conocerá en Nueva York como "Green Guerrilla" (Morán, 2010).

En la década de los setenta también en muchas ciudades europeas arraiga esta filosofía ecologista y se organizan iniciativas similares a través del movimiento "Ciyt farms and Community gardens" donde el cultivo y la cría de animales se integran en los entornos urbanos (Villace et al., 2014). Con la crisis social, política y económica de finales del primer decenio del siglo XXI, especialmente en los países del sur de Europa, la agricultura urbana cobra gran ímpetu, volviéndose cada vez más importante para los habitantes de las ciudades, como ha puesto de manifiesto Partalidou (2017) en un análisis de distintas experiencias de huertos urbanos en el norte de Grecia, o Espinosa (2017) para la ciudad de Alicante (España).

En España, la agricultura urbana no se desarrolló de la misma forma que había ocurrido en otros países europeos, a pesar de las crisis económicas y bélicas desarrolladas a lo largo del S. XX. Aquí el proceso de industrialización fue tardío, las migraciones campo-ciudad fue una dinámica constante hasta la década de los 60 del siglo XX, permaneciendo durante largo tiempo las ciudades rodeadas de las tradicionales huertas. No obstante algunos investigadores consideran que sí existió en España un mecanismo que se puede asimilar al de los "huertos para pobres" europeos y fue los llamados "huertos familiares" impulsados por el Instituto Nacional de Colonización, aunque con un funcionamiento y planteamiento diferente a los europeos. Estos tuvieron un carácter marcadamente rural, fueron concebido como pequeñas parcelas de regadío próximas a un poblado (Valle, 1978).

En la década de los 80 del siglo XX, dos estudios realizados por Baigorri et al. (1983) en las áreas metropolitanas de Barcelona y Madrid constatan la existencia de huertos urbanos y 
periurbanos que habían surgido de forma espontánea, en precario, al margen de cualquier regulación y teniendo como telón de fondo la crisis económica y energética de los años 70, que hizo aumentar considerablemente las tasas de paro.

Pero no será hasta las últimas décadas del siglo XX, con más de un siglo de retraso respecto a otros países europeos, cuando se desarrollen las primeras iniciativas de huertos urbanos en el sentido actual. Dentro de ellas, dos iniciativas hay que señalar, una con un marcado carácter institucional, "los Huertos de Ocio del Caserío de Henares", promovida por la Comunidad de Madrid (1987) y otra, "el Parque de Miraflores en Sevilla" que es el huerto urbano más antiguo de España (1983) (Puente, 2012), que surge como iniciativa popular. A lo largo de los años 90, diversas iniciativas de movimientos sociales y ciudadanos son asumidas por instituciones locales y se ponen en marcha actuaciones de huertos urbanos como la Xarsa d'Horts Urbans de Barcelona o las Huertas de Olarizu en Vitoria-Gasteiz, etc.

Como indica Ballesteros (2014) y Espinosa (2017) fue la crisis económica-financiera y el estallido de la burbuja inmobiliaria los que propician el mayor desarrollo de actuaciones o zonas de huertos. Razones a las que hay que sumar otras, como el resurgir de voces cada vez más críticas con un modelo agroalimentario insostenible, el deterioro ambiental, los movimientos sociales en favor de la soberanía alimentaria y la búsqueda de ciudades más resilientes. Al principio, estos proyectos estaban destinados principalmente a los pensionistas, incluidos los extranjeros procedentes de países con una larga tradición de asignaciones urbanas. A medida que la recesión económica se intensificó en 2009, las asignaciones tuvieron que redefinir sus objetivos en un entorno social ahora definido por el alto desempleo y el empobrecimiento. Hoy, la mayoría de los proyectos se dirigen a personas en riesgo de pobreza y exclusión social y sus funciones principales son productivas, terapéuticas y educativas. Igualmente la crisis económica mundial de 2008 contribuyó de alguna manera a la revaluación del uso de la tierra agrícola, aunque el espectro de la especulación de la tierra todavía está muy presente (Espinosa, 2017).

Según un sondeo realizado por la consultora GEA 21 (Grupo de Estudios y Alternativa) los huertos urbanos se están expandiendo por todas las ciudades españolas. Se ha pasado de 1280 huertos urbanos en el año 2000 a casi 30000 en 2017 (28 865), habiendo multiplicado la superficie por 12,2 (3 $103254 \mathrm{~m}^{2}$ ) y el número de municipios donde se desarrollan han pasado de 8 a 369 en el año 2017 (Ballesteros, 2018). Ello pone de manifiesto que los huertos urbanos han dejado de ser un fenómeno testimonial en España para convertirse en un movimiento con un fuerte arraigo en muchas ciudades. En su distribución territorial son las CC. AA. de Andalucía y 
Valencia las que ocupan las primeras posiciones en el ranking español, sumando el 34,2\% de los huertos urbanos de España, el 40,7 \% de las parcelas y el 41 \% de la superficie total.

\subsection{Concepto de agricultura urbana}

A pesar de la obvia situación geográfica dar una definición de la agricultura urbana es una cuestión ardua teniendo en cuenta la variedad de formas existentes. Aunque el fenómeno de la agricultura urbana y periurbana ha sido tratado en las últimas décadas, desde distintas ciencias, no se ha llegado a una definición consensuada, manteniéndose abierto el debate (Fantini, 2016).

El término de agricultura urbana y periurbana fue propuesto por la FAO para referirse a una actividad que tradicionalmente se ha vinculado a los países pobres como estrategia de seguridad alimentaria y de desarrollo justo y sostenible (Fantini, 2006), pero que también está teniendo franca expansión en los países desarrollados aunque con otros objetivos. En éstos, la agricultura urbana ha pasado de ser una práctica necesaria para la subsistencia, de tener un valor recreativo en la década de los 70 del siglo XX, a adquirir en la actualidad el objetivo de hacer más sostenibles las ciudades y lograr la inserción de la naturaleza en ellas (Morán, 2008-2009). Se trata, pues, de una agricultura con un planteamiento polifuncional en el que se plasma valores sociales, culturales y ecológicos (Colging \& Barthel, 2013; Soler, 2014). Y es precisamente en esta multifuncionalidad donde reside una de las dificultades en establecer una definición normalizada que sirva de forma universal.

Las múltiples definiciones existentes son confusas, ambiguas e incompletas, aunque en continuo proceso de cambio y adaptación a las nuevas realidades. Estas van desde definiciones muy generalistas que no llegan a abarca toda la casuística de la agricultura urbana ni su manifestación espacial (Arosemena, 2012; FAO, 1996), hasta las más recientes que contemplan el carácter polivalente y multifuncional de esta actividad y la entienden como una actividad multifuncional y multicomponente (Fleury, 2006; Ingersoll, 2007; FAO, 2014).

En un esfuerzo por definir la agricultura urbana, Mougeot (2001) cotejó un amplio espectro de definiciones a fin de determinar cuáles eran los elementos claves que las definiciones contemplaban, señalando el tipo de actividades económicas, las categorías y subcategorías de productos alimentarios/no alimentarios, la ubicación o la situación intra o periurbana, las características técnicas y formales, los tipos de sistemas y escala de la producción y más recientemente se incluye su integración e interacción con el sistema ecológico, social y económico de la ciudad. 
De todos estos elementos, como Mougeot indica, el más común en las definiciones de agricultura urbana es la ubicación, aunque también es la causa más grande de conflicto. Son pocas las investigaciones en las que a la hora de definir esta actividad separan los conceptos de agricultura urbana y periurbana o si lo hacen usan criterios muy variados. Ello ha provocado que en muchas investigaciones se usen indistintamente ambos conceptos cuando en realidad a lo que hace referencia es a la agricultura presente dentro de la trama urbana (agricultura urbana). Sería necesario, como muchos investigadores indican, diferenciar con precisión a qué agricultura se hace referencia cuando se utiliza el término de agricultura urbana, aspecto esencial desde el ámbito geográfico.

En este sentido, una de las primeras definiciones sobre agricultura urbana fue dada por la FAO (1996) en la que aludía conjuntamente a la agricultura urbana y periurbana (Tabla 1). Con posterioridad, en 1999, el Comité de Agricultura (COAG-FAO) elaboró un informe específico sobre la Agricultura urbana y periurbana en el que ya se definía separadamente ambos términos, categorizando a la primera como pequeñas áreas ubicadas dentro del perímetro urbano, destinadas a la producción de productos agrícolas o la cría de pequeños animales para consumo propio o para el comercio. En cuanto a la agricultura periurbana, la definió como áreas de producción en las periferias de las ciudades, que podrían ejercer intensivamente las actividades, tenga o no destino comercial (FAO, 1999). La crítica en cuanto a esta definición vendría sobre la subjetividad del término periferia. La definición del límite exterior de la agricultura periurbana dependerá del criterio aplicado y se han utilizado varios en investigaciones del pasado. ${ }^{2}$ Pero el grado de desarrollo de la infraestructura y el sistema de transporte local tiende a ser la clave para definir el "radio" de esta zona alrededor de la ciudad (Losada et al., 1998; Moustier, 1999).

Una de las definiciones que más transcendencia ha tenido por la cantidad de investigaciones y organismos que hacen referencia a ella es la elaborada por Mougeot (2006) en colaboración con la FAO, aunque en ella se alude conjuntamente a la agricultura urbana y periurbana. En el mismo sentido se pronuncia el Grupo Nacional de Agricultura Urbana de Cuba, uno de los países a la vanguardia en dichos temas (Tabla 1).

2 Se han utilizado variados criterios, desde el modelo de Von Thünen (1826) que ha ido perdiendo validez ante los cambios territoriales, de transporte y socioeconómicos, pasando por la definición de la OCDE (1979) para la que agricultura urbana era la situada en un área que va desde 10 a $20 \mathrm{~km}$ del núcleo urbano en función de los habitantes de éste, o modelos más recientes, como el propuesto por Nahmias y Le Caro (2012) que basado en la distancia al centro de la ciudad, integra también la funcionalidad de la agricultura y el tipo de comercialización (Yacamán, 2018). 
Desde el campo estrictamente académico encontramos varias tendencias. Por un lado, las menos, aparece un grupo de trabajos científicos que circunscriben la agricultura urbana únicamente al espacio intraurbano (Garzón, 2011; Cantor, 2010; Mullins, 2010; Torres, 2000), por otro lado, aparece aquel otro grupo que la define genéricamente como la que se desarrolla en áreas urbanas sin precisar si se refiere a la que se practica en zona intraurbana o periférica (Moreno, 2007; Arosemena, 2012) y, por último, existe otro grupo de investigaciones (Dimuro et al., 2013) en las que aun reconociendo las diferencias morfológicas, productivas y socioeconómicas que existen entre la agricultura urbana y periurbana, no obstante las definen conjuntamente (Tabla1).

Las diversas definiciones de agricultura urbana son prueba de la inexistencia de una definición universal que evoque un consenso. Esto, sin embargo, no quita la necesidad de una definición, que sirva como herramienta mental destinada a realzar el entendimiento y a describir la realidad compleja de la actividad agrícola urbana y periurbana.

Como indica la FAO (1999), el uso indiscriminado de ambos términos se puede deber a los aspectos que ambos tipos de agricultura tienen en común y las diferencias se establecen en relación a lo se puede denominar agricultura rural y la de proximidad a grandes asentamientos humanos. Ambos conceptos se asemejan y se diferencian en aspectos relacionados principalmente con los tipos de cultivo y la escala de producción y de venta, estos últimos condicionados por la extensión del terreno cultivado. La agricultura urbana se refiere al cultivo de superficies muy reducidas situadas en el perímetro urbano (solares vacíos, patios, terrazas) y la pequeña cría de animales domésticos y es practicada casi exclusivamente por personas que no son agricultoras que viven y trabajan en la ciudad y tiene como objetivo el consumo propio o la venta en el mercado de proximidad, cultivando especialmente productos hortícolas. En cambio, la agricultura periurbana son extensiones de terrenos más amplias, siendo su objetivo la comercialización de los excedentes, cultivando una gama más amplia de productos (Hemi Zaar, 2011). 
Tabla 1. Diferentes conceptualizaciones de Agricultura Urbana

\begin{tabular}{|c|c|}
\hline AUTORES/ORGANISMOS & DEFINICIONES \\
\hline FAO (1996) & $\begin{array}{l}\text { "Las prácticas agrícolas que se llevan dentro de los límites o en } \\
\text { los alrededores de las ciudades de todo el mundo e incluye la } \\
\text { producción y en algunos casos el procesamiento de productos } \\
\text { agropecuarios, pesqueros y forestales". }\end{array}$ \\
\hline $\begin{array}{l}\text { FAO. Comité de agricultura } \\
\text { (1999) }\end{array}$ & $\begin{array}{l}\text { "Pequeñas superficies [...] situadas dentro de una ciudad y } \\
\text { destinadas a la producción de cultivos y la cría de ganado } \\
\text { menor [...] para el consumo o para la venta en mercados de la } \\
\text { vecindad". }\end{array}$ \\
\hline Torres (2000) & $\begin{array}{l}\text { "La producción a pequeña escala de alimentos de origen } \\
\text { vegetal, animal en áreas intraurbanas" }\end{array}$ \\
\hline Mougeot (2006) & $\begin{array}{l}\text { "Aquella agricultura que está ubicada dentro de una ciudad } \\
\text { (intraurbana) o en la periferia (periurbana) y en la que se cultiva } \\
\text { una diversidad de productos alimentarios y no alimentarios (re) } \\
\text { utilizando en gran medida recursos humanos y materiales, } \\
\text { productos y servicios que se encuentran en y alrededor de } \\
\text { dicha zona, y a su vez provee recursos humanos y materiales, } \\
\text { productos y servicios en gran parte a esa misma zona urbana". }\end{array}$ \\
\hline $\begin{array}{l}\text { Grupo Nacional de } \\
\text { Agricultura Urbana cubano } \\
\text { (2001) }\end{array}$ & $\begin{array}{l}\text { "La producción de alimentos dentro del perímetro urbano y } \\
\text { periurbano aplicando métodos intensivos [...].basada en } \\
\text { prácticas sostenibles que permitan el reciclaje de los } \\
\text { desechos". }\end{array}$ \\
\hline Moreno (2007) & $\begin{array}{l}\text { "El cultivo, procesamiento, distribución y consumo de } \\
\text { productos agrícolas dentro del área de la ciudad, empleando } \\
{[\ldots] \text { recursos insuficientemente utilizados como terrenos baldíos }} \\
{[\ldots] \text { ". }}\end{array}$ \\
\hline Mullins (2010) & $\begin{array}{l}\text { "Espacio que se encuentra en un territorio urbano o no rural } \\
\text { destinado al cultivo con cualquier tipo de fin: productivo, } \\
\text { autoconsumo, educativo [...]" }\end{array}$ \\
\hline Cantor (2010) & $\begin{array}{l}\text { "La práctica agrícola y pecuaria en áreas intra y periurbanas de } \\
\text { las ciudades, que por iniciativa de los productores, afincados } \\
\text { muchas veces en los barrios marginales [...], utilizan los mismos } \\
\text { recursos locales [...] con el fin de generar productos de } \\
\text { autoconsumo y también destinados a la venta en el mercado". }\end{array}$ \\
\hline Garzón (2011) & $\begin{array}{l}\text { "[...] La práctica agrícola que se realiza en espacios urbanos } \\
\text { dentro de la ciudad o en los alrededores (agricultura urbana y } \\
\text { periurbana), en zonas blandas (como antejardines, lotes) o en } \\
\text { zonas duras (terrazas, patios), utilizando el potencial local [...] } \\
\text { con el fin de promover la sostenibilidad ambiental y generar } \\
\text { productos alimenticios limpios para el autoconsumo y } \\
\text { comercialización [...]" }\end{array}$ \\
\hline Arosemena (2012) & $\begin{array}{l}\text { "Toda actividad relacionada con el cultivo de alimentos próximo } \\
\text { a la ciudad y en el que el destino final de la producción sea } \\
\text { abastecer a dicha ciudad". }\end{array}$ \\
\hline Dimuro et al. (2013) & $\begin{array}{l}\text { "Es la que se realiza en el sistema urbano bien en la trama } \\
\text { urbana consolidada o en el periurbano. Existen diferencias } \\
\text { morfológicas, productivas y socioeconómicas entre ellas, pero } \\
\text { ambas deben entenderse como actividades desarrolladas[...] } \\
\text { como agricultura urbana en sentido amplio" }\end{array}$ \\
\hline
\end{tabular}

Fuente: elaboración propia a partir de autoras/es citadas/os 
El análisis de la agricultura urbana que se desarrollará en la presente investigación se corresponde con las pequeñas parcelas que se ubican dentro de los límites del espacio urbano que realizan prácticas ecológicas alternativas, en las que se obtiene baja producción y que son destinadas al autoconsumo, al intercambio con otros hortelanos o a la cesión a los vecinos. Son cultivados por población que no es agricultora, siendo su fin primordial lúdico, aunque algunos de los huertos han diversificado sus motivaciones iniciales e incluyen objetivos de carácter social, de investigación y formación.

\section{La tradición de las huertas en la ciudad de Málaga y su revitalización actual}

Málaga es una ciudad del sur de España, localizada en una pequeña bahía del monte Gibralfaro, dominando los últimos tramos de los ríos Guadalmedina y Guadalhorce. Enclavada en la Cordillera Bética, la ciudad tanto por el norte, como por el este, se encuentra rodeada por los Montes de Málaga que han forzado a una expansión hacia el oeste, en las tierras del valle del río Guadalhorce, si bien la ciudad también ha ido colonizando las vertientes.

En esta ciudad existen testimonios y vestigios de huertas fértiles desde tiempos remotos, claramente manifiestos en la época musulmana. En este momento hay vestigios que toda la zona urbana, más allá de las murallas, estaba rodeada de huertas. Huertas como la del Molinillo, de Villazo, de Natera, de Abivar rodeaban la ciudad y también se insertaban en el tejido urbano de los arrabales. Al norte de la ciudad se situaba el arrabal de Fontanalla donde junto a zonas de huertas existía un área delimitada para guardar el ganado, y el Ejido donde irá acomodándose el pastoreo cercano. Al otro lado del río Guadalmedina se situaba el arrabal de Al-Tabannim o de los Mercaderes de la Paja, correspondiente a los actuales barrios del Perchel y la Trinidad, que se extendía hacia el sur hasta la playa, donde hay constancia de la existencia de pozos, de noria y canales de drenaje, así como redes de albercas jerarquizadas para la distribución controlada de riego (PGOU, 2011). Este barrio jugaría un papel relevante como abastecedor de productos a la ciudad (López et al., 2013). El espacio para el cultivo también se extendía más allá de las inmediaciones de la ciudad, colonizando las vertientes de los montes de Málaga (Figura 1). 


\section{Figura 1. Málaga árabe conforme al plano de Rafael Mitjana}

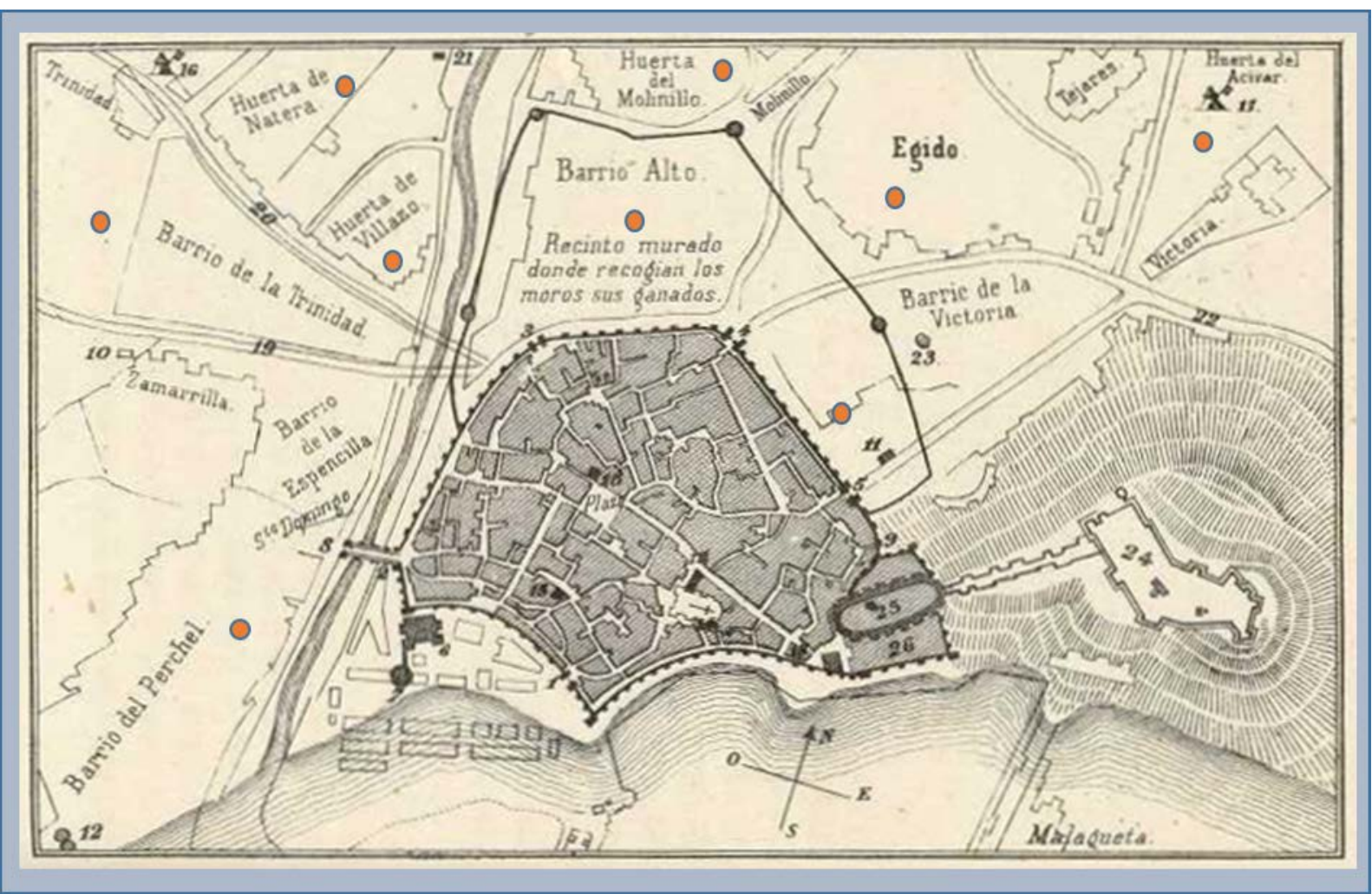

Fuente: IECA (2016), Junta de Andalucía

En la época de los repartimientos fue frecuente la creación de conventos en la ciudad en los que se les proporcionaba a los clérigos tierras, huertas y villas para el sostenimiento de la orden. Así ocurrió con el convento e iglesia de los trinitarios en el barrio de la Trinidad, el convento e iglesia de Santo Domingo en el barrio del Perchel que tuvo su origen sobre las siete huertas que, a la hora de los Repartimientos de Málaga, los Reyes Católicos adjudicaron a los dominicos, o el convento de los franciscanos capuchinos de Málaga en el barrio de Capuchinos que también surgió tras la conquista cristiana de la ciudad y cuando comienza a poblarse a partir del primer tercio del S. XVIII, la zona estaba ocupada por huertas de patatas, verduras, flores y por vaquerías por la abundancia de pasto para el ganado (Figura 2). 


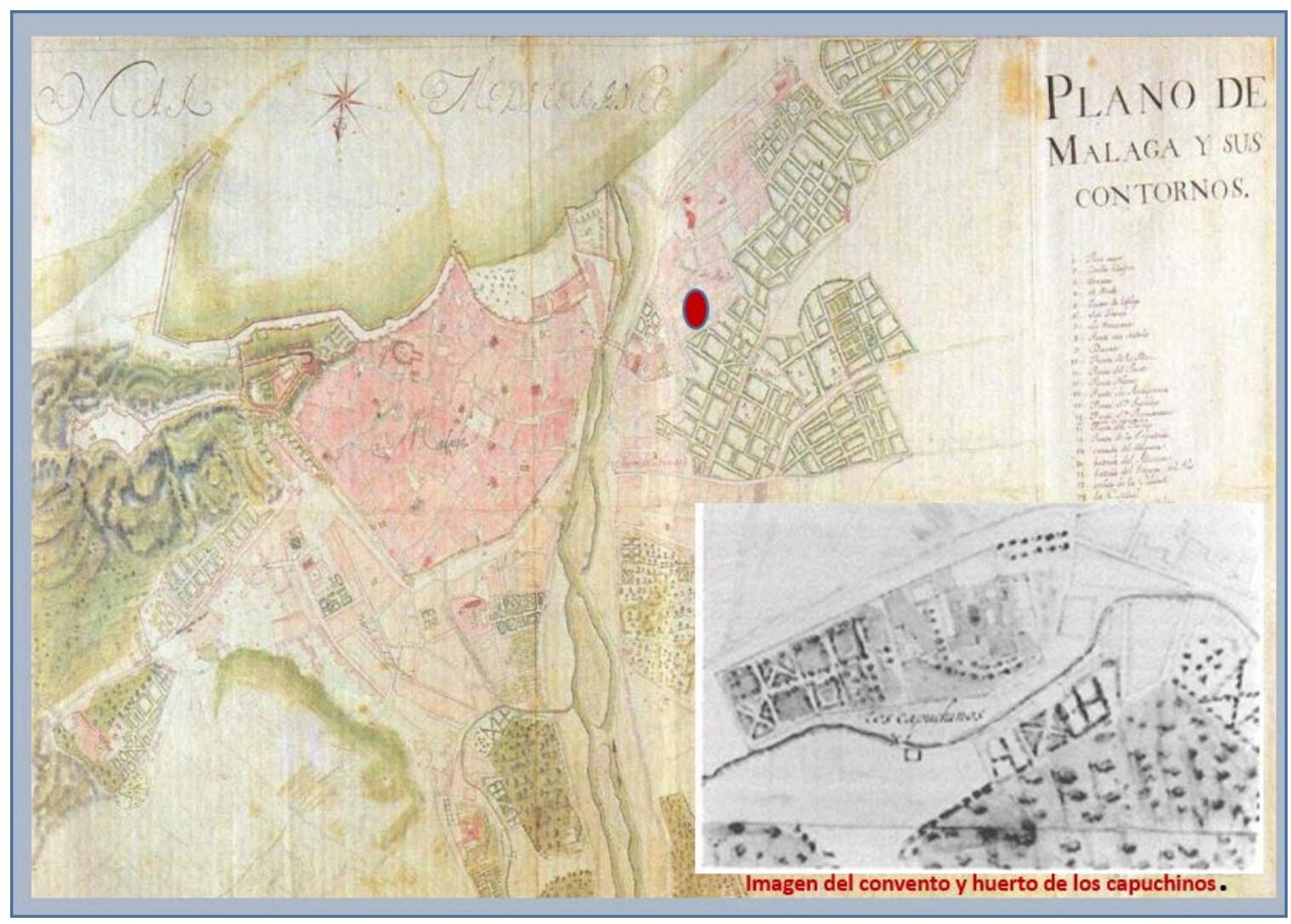

Fuente: Cabrera, F. \& Olmedo (2019)

Un hito importante en las huertas históricas de Málaga lo marca la zona norte de la ciudad que permaneció prácticamente con sus huertas y haciendas hasta que en el año 1924 se empieza a urbanizar siguiendo los preceptos de la "Ciudad Jardín". En uno de sus barrios, el de Ciudad Jardín, en la actualidad perviven con claridad las huellas de las grandes fincas del pasado. Fincas que colonizaban con tierras de viñas y de labor los cerros sobre el río Guadalmedina, favorecidas por la vecindad del Acueducto de San Telmo. Muchos de sus barrios actuales conservan todavía los nombres originales de estas propiedades: los Casinis, los Cipreses, o la finca de Huerta Nueva (Muñoz, 2006). Otra pista del pasado es el nombre del Arroyo Quintana que recuerda a esta finca que perteneció a la familia de Domínguez Quintana y que hoy en día es una dependencia del servicio de Parques y Jardines del Ayuntamiento de Málaga (Figura 3). 
Figura 3. Plano de Málaga 1900 y Barrios

del norte de la ciudad que coinciden con huertas históricas

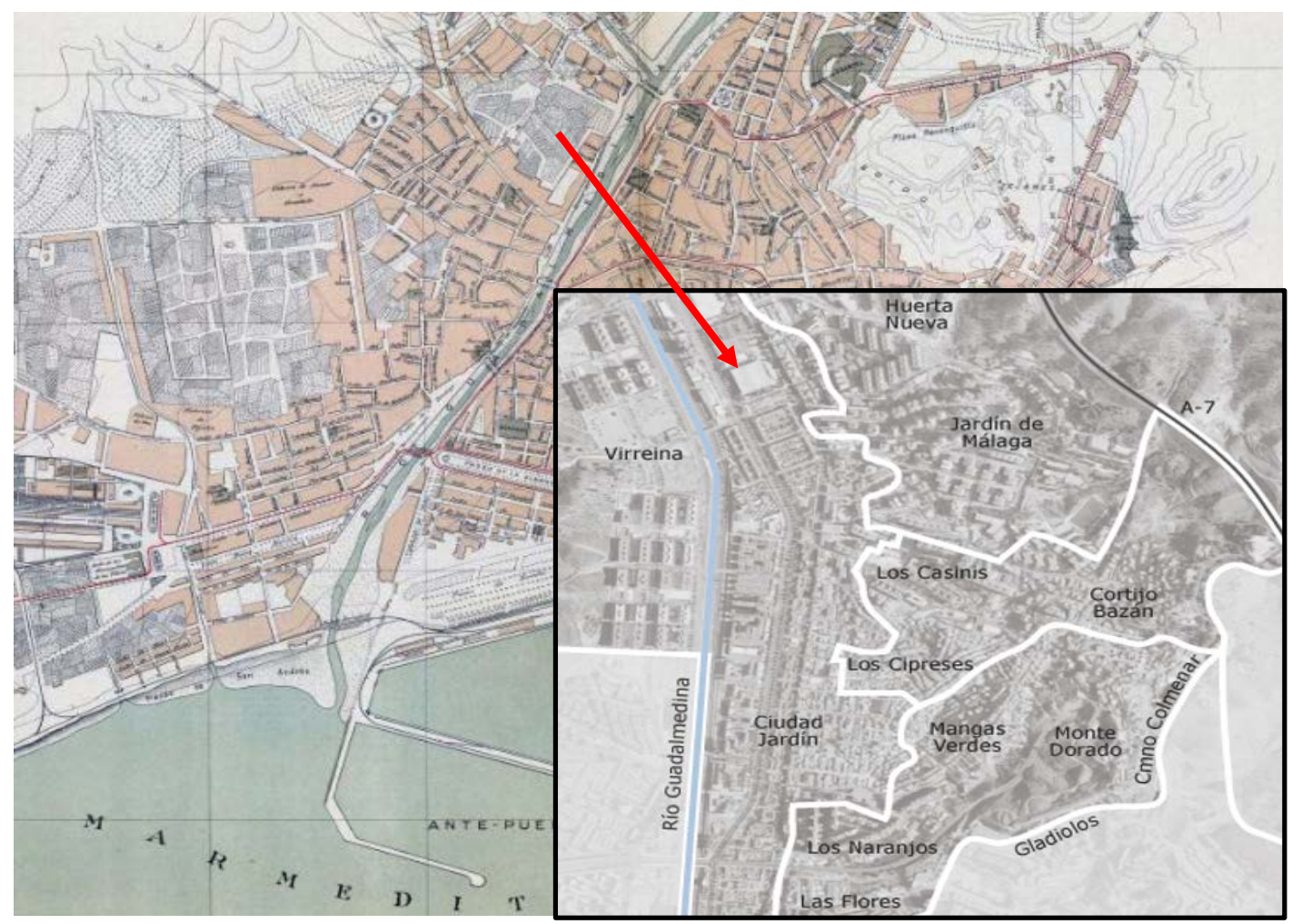

Fuente: eblancooliva (2016)

Todas estas zonas de huertas, tanto las situadas a la orilla oeste del Guadalmedina como al norte del casco histórico, se mantuvieron hasta bien adentrados en el siglo XX (Figura 4). El éxodo rural, como en el resto de España, fue suplantando poco a poco huertas, vaquerías y ruinas industriales por barrios obreros poblados de forma masiva por gente proveniente de zonas rurales. El resultado fue el de un urbanismo mal planificado, que se realizó únicamente con intereses empresariales especulativos, aprovechando el bajo coste del suelo y buscando el máximo beneficio.

De la importancia que tuvieron las huertas en la ciudad de Málaga da cuenta el Plan de Ensanche y Remodelación de la ciudad de José Moreno Monroy (1861) donde una de las actuaciones contempladas era reordenar las huertas más cercana de la ciudad (García, 2015). En época más reciente la impronta de las huertas urbanas se refleja en el PGOU de 1983, en el que uno de los principales retos fue poner orden al desorden de los barrios-dormitorio (Moreno et al, 1989) y que respondían a la delimitación de fincas agrícolas de las que aún se conservan nombres, como Jardín de la Abadía y Cortijo Vallejo (distrito Carretera de Cádiz), Granja Suárez (distrito Bailén-Miraflores) o Cortijo Bazán (distrito Ciudad Jardín). 


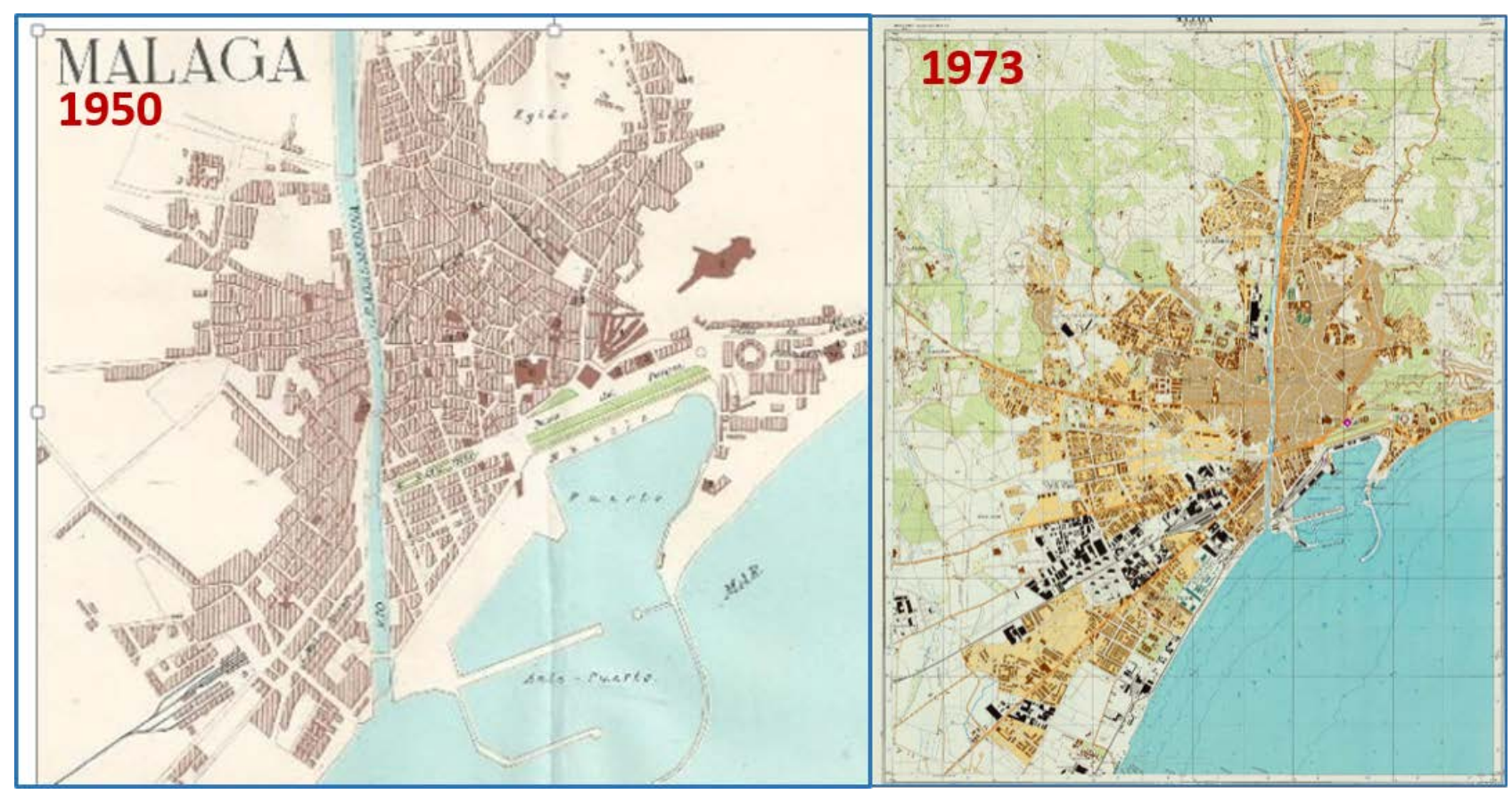

Fuente: Junta de Andalucía (2015)

Los sucesivos PGOU $(1997,2011)$ de la ciudad desarrollarán nuevos proyectos urbanísticos que otorgarán una orientación metropolitana a la ciudad, como la ampliación de la Ciudad Universitaria y el Parque Tecnológico de Andalucía Un momento destacable en el desarrollo urbanístico de la ciudad lo constituyó el "boom inmobiliario 1997-2007" en el que la actividad constructora en Málaga es de gran intensidad. El crecimiento urbanístico de la ciudad en la década de 2000-2010 incorporó 96346 nuevos edificios, con lo que en el año 2010 más de un $25 \%$ de todos los edificios existentes tenían 10 o menos años. Crecimiento que solo fue superado en España por Murcia.

Este desarrollo urbanístico de Málaga capital en el último medio siglo no ha ido al unísono de su crecimiento demográfico, de manera que mientras el número de habitantes no ha llegado a duplicarse desde 1950, la superficie urbanizada se ha multiplicado por diez en este período. En 1950 la población de Málaga era de 276222 habitantes distribuidos en unas 623 hectáreas. Actualmente alberga unos 574000 habitantes sobre 7225 hectáreas, superficie que se ha creado en un $75 \%$ consumiendo zonas agrarias y en menor medida zonas forestales. Siendo de 7,6 el número de $\mathrm{m}^{2}$ de zonas verdes por habitantes (OMAU, 2016a), lejos de los $15 \mathrm{~m}^{2}$ que recomienda la UE y los 10,4 $\mathrm{m}^{2}$ que marca la LOUA (Ley de Ordenación Urbanística de Andalucía). 
En este proceso urbanizador, un elemento a tener en cuenta es que cuando este avanza no siempre lo hace de manera uniforme. En la medida en que marcha la colonización en el interior de la trama urbana sobreviven reductos de espacios vacíos que quedan en medio de la malla edificada. Un ejemplo claro ha sido el estallido reciente de la burbuja inmobiliaria que ha supuesto un fuerte parón de la expansión urbanizadora, que se ha traducido, por un lado, en una menor presión de los privados sobre el espacio urbano y, por otro lado, en la generación y ampliación de espacios libres que requieren nuevas formas de uso y dejen de representar contenedores de pobreza y degradación Como indica Fantini (2016), a tal fin la agricultura urbana y periurbana puede representar un fenómeno muy significativo de respuesta a esta incongruencia generada por la crisis urbanizadora.

En este contexto, a partir del año 2011, desde la Gerencia de Urbanismo del Ayuntamiento de la capital surge la iniciativa de revitalizar los espacios subutilizados y/o degradados a través de huertos urbanos como una alternativa sostenible tanto desde el punto de vista medioambiental, social y económico, bajo la financiación del programa de empleo de la Junta de Andalucía (Plan Proteja) (Fernández, 2013). En este momento se pusieron en marcha cuatro huertos urbanos, a los que paulatinamente se han ido sumando otros tantos de índole privado y público, hasta los 19 que hemos inventariado en el momento actual.

Junto al desarrollo de huertos urbanos, el interés de la ciudad por la sostenibilidad medioambiental se ha manifestado en variados proyectos e iniciativas que fomentan el desarrollo y conocimiento de la agricultura urbana, tanto por parte de distintas administraciones (Ayuntamiento, Diputación, Universidad, etc.) como desde la iniciativa privada.

El ayuntamiento de Málaga ha puesto en marcha el proyecto "Pasaporte Verde: Huertos escolares: siembra y aprende" que desde su inicio, curso 2016-2017, han participado en él 86 centros escolares.

Por su parte, la Diputación de Málaga promueve iniciativas que inciden directamente en la mejora medioambiental no sólo de la capital malagueña sino de toda la provincia. En 2013 puso en marcha el Centro de Innovación Social "La Noria" donde se creó un vivero, un aula formativa ("Aula Vivero La Salvia") y una huerta urbana.

Desde el ámbito tanto privado como público han surgido muchas organizaciones y proyectos que incluyen entre sus objetivos programas de sostenibilidad ambiental en los que la actividad agraria está muy presente ("EcoHuerto El Rabanito" "CreaHuertas" "Aulaga", "Huertum", el primer proyecto europeo de agricultura social). 
Por su parte, la Universidad de Málaga (UMA) también se ha sumado a este movimiento por la sostenibilidad urbana desde el Vicerrectorado de Smart Campus, cuyo objetivo es hacer de la Universidad de Málaga un referente de sostenibilidad. Este compromiso se inició en 2012 con el proyecto de "J-Aulas Abiertas" cuyo fin era la creación de un espacio al aire libre en el que desarrollar una serie de encuentros, actividades, debates y jornadas con la visión de convertirse en agentes de cambio. Seguido por la creación en el curso 2013-2014 en la Facultad de Ciencias, de un huerto de uso docente.

Más recientemente destacan dos proyectos de gran envergadura: el "Proyecto de Islas y Sendas Verdes" y la creación de un "Huerto urbano y un parque frutal" en el Campus Universitario de Teatinos y su ampliación para uso de la comunidad universitaria. Con el primero se pretende crear áreas verdes próximas a los diferentes centros del Campus universitario de Málaga, así como caminos verdes que interconecten las diferentes islas verdes. Hasta el momento se ha realizado tres ediciones de este proyecto en las que se ha construido una isla verde en el entorno de las Facultades de Turismo y Ciencias de la Comunicación (Figura 5), habiendo tres en construcción y cuatro pendientes de ejecución. El segundo es un proyecto formativo y de investigación y constituirá uno de los nodos fundamentales dentro del sistema de Sendas Verdes. Para ello se ha reservado unos $22000 \mathrm{~m}^{2}$ de superficie, donde $2500 \mathrm{~m}^{2}$ se destinará a la construcción de un huerto comunitario y $11773,3 \mathrm{~m}^{2}$ a otro de investigación.

\section{Figura 5. Isla Verde en el Campus Universitario de Málaga}

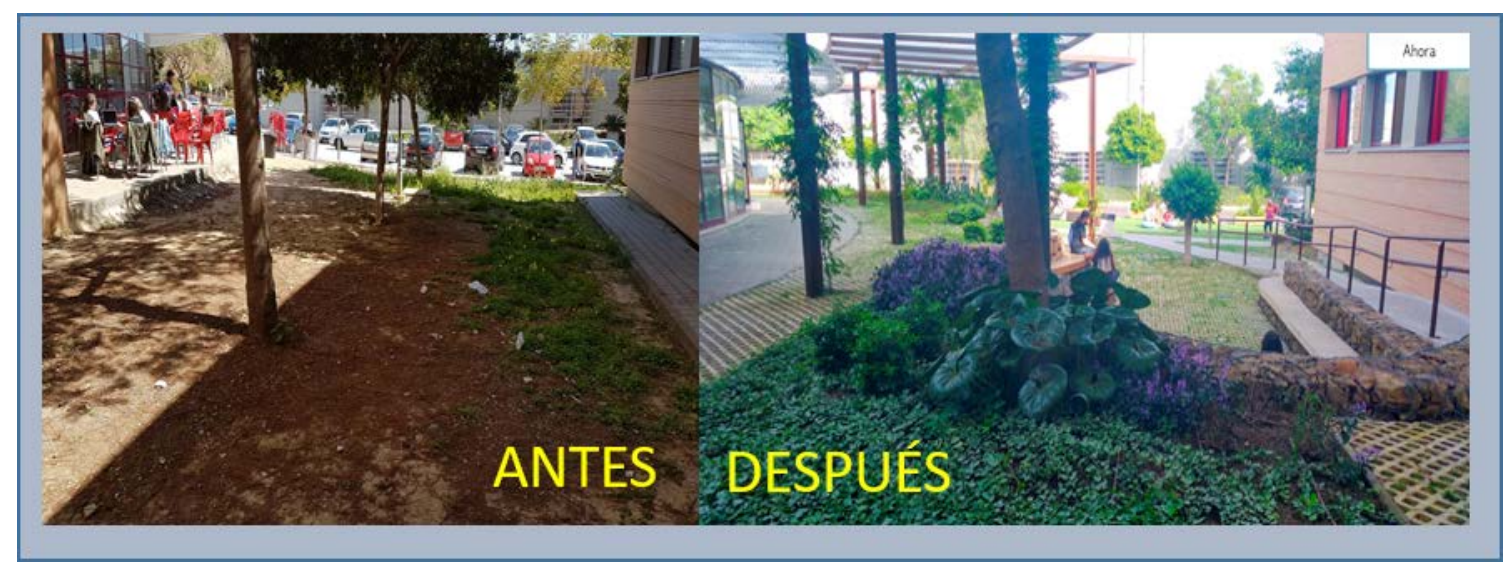

Fuente: Universidad de Málaga. Vicerrectorado de Smart-Campus (2019) 


\section{Los huertos urbanos en la ciudad de Málaga}

\subsection{Localización y tipología}

Hasta el momento actual se ha podido catalogar 19 huertos urbanos en la ciudad de Málaga ${ }^{3}$ distribuidos en 8 de los 11 distritos que conforman la ciudad. Su localización permite diferenciar dos áreas; por un lado, los huertos urbanos insertos en el tejido más denso, compacto y tradicional de la ciudad (distritos Centro, Este, Bailén-Miraflores, Palma-Palmilla, Carretera de Cádiz) que responden a una localización totalmente intraurbana y, por otro lado, los que se expanden hacia la periferia urbana (distritos de Teatinos-Universidad, Puerto de la Torre), llegando incluso al área periurbana (distrito de Campanillas).

Estos distritos con huertos presentan características urbanísticas y sociodemográficas muy variables, pudiéndose encontrar desde barrios tradicionales a barrios de reciente edificación con tipología de bloques abiertos, amplios bulevares y zonas verdes, o de ciudad dormitorio con viviendas unifamiliares aisladas. Los huertos urbanos localizados en la zona más compacta de la ciudad tienen en común su situación en zonas de bajo nivel de calidad ambiental por su intenso proceso constructivo. Algunos de ellos (distrito Carretera de Cádiz) es un claro ejemplo del urbanismo del desarrollismo, donde predominan las viviendas en bloques altos con escasas zonas verdes, levantados sin plan urbanísticos y destinado a la clase obrera; otros (PalmaPalmilla) surgieron durante las décadas de los 60 y 70, afectados por algún plan urbanístico, con el objetivo de erradicar el chabolismo del centro urbano, conformando en la actualidad zonas que padecen un considerable nivel de deterioro urbanístico.

Estos 8 distritos se reparten el 89,3\% de la población de la ciudad, siendo los distritos de localización claramente intraurbana los que presentan las mayores densidades de población por encima de los 11000 hab $/ \mathrm{km}^{2}$, salvo los distritos de Palma-Palmilla (1214 hab $/ \mathrm{km}^{2}$ ) y Este $\left(439,9 \mathrm{hab} / \mathrm{km}^{2}\right)$. Mientras que sólo los distritos Centros, Teatinos-Universidad y Campanillas tienen superficie dedicadas a zonas verdes por encima de la media urbana $\left(7,60 \mathrm{~m}^{2} / \mathrm{hab}\right)$ (Tabla 2).

3 De los 19 huertos, 14 se encuentran totalmente activos, tres de ellos tienen una actividad intermitente, uno está en sus inicios y otro en fase de creación. 
Tabla 2. Características de los distritos donde se localizan los huertos urbanos

\begin{tabular}{|c|c|c|c|c|c|c|c|c|}
\hline ZONAS & DISTRITOS & $\begin{array}{l}\text { POBL. } \\
\text { TOTAL }\end{array}$ & $\begin{array}{l}\text { ZONAS } \\
\text { VERDES } \\
\left(\mathrm{m}^{2} / \mathrm{hab}\right)\end{array}$ & $\begin{array}{l}\text { DENSIDAD } \\
\left(\mathrm{hab} / \mathrm{Km}^{2}\right)\end{array}$ & $\begin{array}{c}\text { POBL } \\
0-14 \\
\text { AÑOS } \\
(\%)\end{array}$ & $\begin{array}{c}\text { POBL } \\
\text { MÁS } \\
65 \\
\text { AÑOS } \\
(\%)\end{array}$ & $\begin{array}{l}\text { RENTA } \\
\text { ANUAL/ } \\
\text { HOGAR }\end{array}$ & $\begin{array}{c}\% \\
\text { POBL } \\
\text { EXTRA } \\
\text { NJERA }\end{array}$ \\
\hline \multirow[t]{5}{*}{ Intra-urbana } & Centro & 81229 & 13,96 & 11511,6 & 13,28 & 19,93 & 21686 & 30,3 \\
\hline & Este & 56137 & 6,62 & 439,9 & 15,25 & 18,44 & 38046 & 8.9 \\
\hline & $\begin{array}{l}\text { Bailén- } \\
\text { Miraflores }\end{array}$ & 60800 & 2,39 & 19805,2 & 14,55 & 19,35 & 22043 & 12,9 \\
\hline & $\begin{array}{l}\text { Palma- } \\
\text { Palmilla }\end{array}$ & 30882 & 1,96 & 1214,5 & 19,55 & 12,90 & 17009 & 6,8 \\
\hline & Car. Cádiz & 115212 & 7,58 & 14263,4 & 14,44 & 18,66 & 25293 & 21,7 \\
\hline \multirow[t]{2}{*}{ Periférica } & $\begin{array}{l}\text { Teatinos- } \\
\text { Universidad }\end{array}$ & 37642 & 12,92 & 6413,8 & 23,78 & 6,75 & 26107 & 2,5 \\
\hline & $\mathrm{Pt}^{\circ}$ Torre & 30781 & 5,34 & 695,5 & 18,29 & 12,81 & 27100 & 2,4 \\
\hline \multirow[t]{2}{*}{ Periurbana } & Campanillas & 18768 & 25,25 & 311,89 & 18,03 & 12,55 & 20041 & 1,6 \\
\hline & Total ciudad & 573832 & 7.60 & 1445 & 15,63 & 17,36 & 24404 & \\
\hline
\end{tabular}

Fuente: elaboración propia a partir de OMAU (2016a, 2016b)

\& Padrón Municipal de habitantes (2018)

Los diferentes barrios presentan características sociodemográficas y económicas diferenciadas. Desde el punto de vista social hay gran distancia entre ellos, por un lado se encuentran los distritos con los menores niveles de renta, es el caso de Palma-Palmilla que con diferencia es el más pobre de Málaga, seguidos por el de Campanillas, Centro y su expansión hacia el de Bailén-Miraflores; frente a estos los distritos periféricos y el distrito Este son los que presentan los valores de renta anual más elevado, por encima de la media urbana, así como los menores índices de envejecimiento y menor presencia de población extranjera, correspondiéndose con los que presentan menores densidades de población y más superficie verde (Tabla 2, Anexo II).

La distribución de los huertos urbanos en la ciudad sitúa en primer lugar a dos distritos contrapuestos por sus características sociodemográficas, los distritos de Teatinos-Universidad y Palma-Palmilla, por ser el primero uno de los distritos periféricos de la reciente expansión urbanística de la ciudad y el segundo uno de los más degradado; a continuación, se sitúa el distrito de Campanillas, de localización claramente periurbana. En estos tres distritos se localizan algo más de la mitad de los huertos de la ciudad (57,8\%). Los restantes huertos se distribuyen por los distritos de Carretera de Cádiz, Centro y Puerto de la Torre con dos huertos cada uno, mientras que con un huerto cada uno aparecen los distritos Este y Bailén-Miraflores (Figura 6, Anexo II). 
Figura 6. Localización y distribución de los huertos urbanos

\section{en los distritos de la ciudad de Málaga}

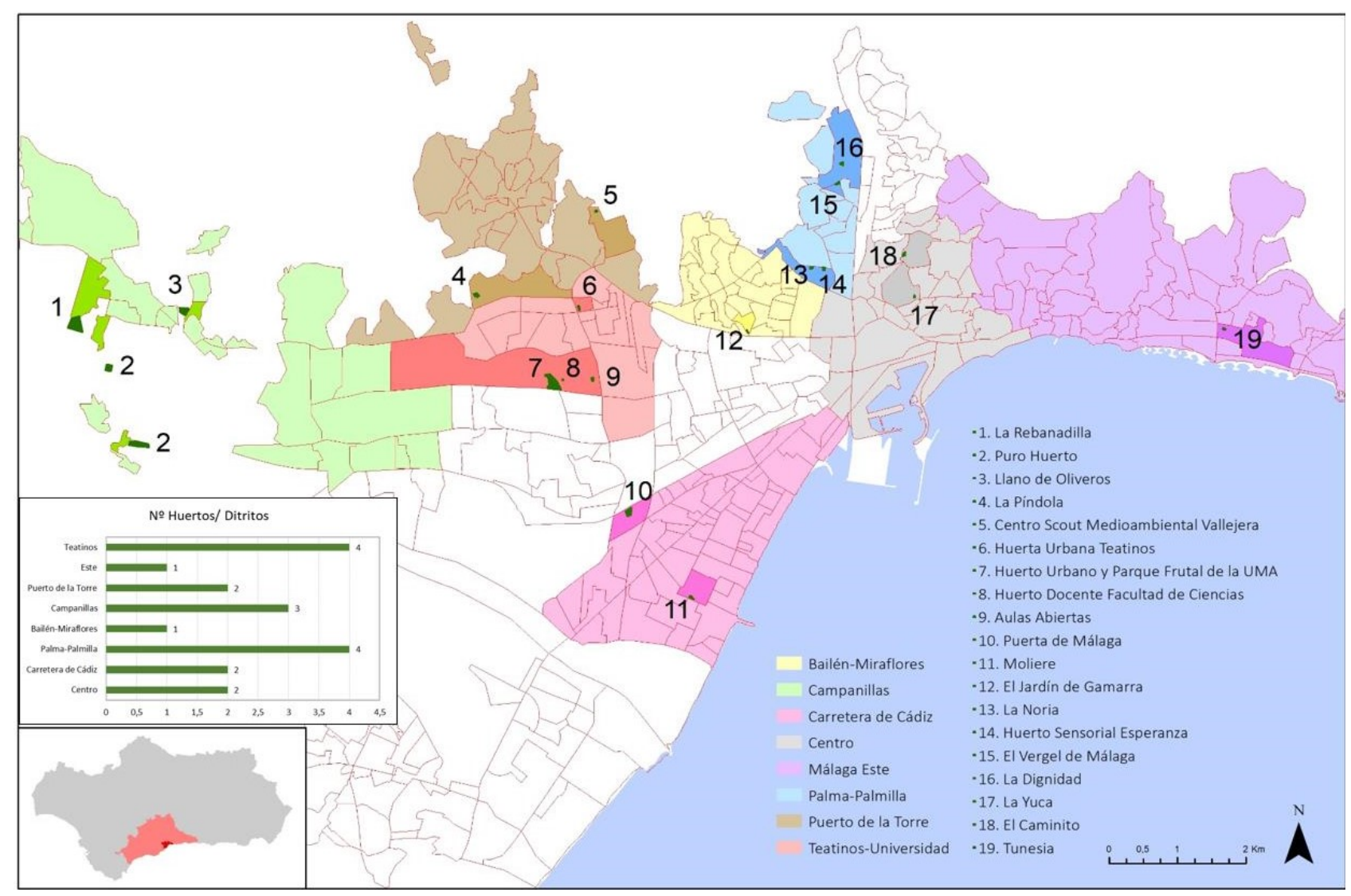

Fuente: elaboración propia

El interés por los huertos urbanos en la ciudad de Málaga se refleja en su evolución en el tiempo. El inicio de los huertos se remonta al año 2011 cuando la Gerencia de Urbanismo del Ayuntamiento puso en marcha la instalación de 3 huertos urbanos y un jardín comunitario que posteriormente incluiría también un huerto urbano en 4 distritos de la ciudad (Carretera de Cádiz, Palma-Palmilla, Centro y Bailén-Miraflores). La idea inicial era disponer de un huerto en cada distrito reconvirtiendo solares improductivos y sucios en zonas de cultivo, pero los impedimentos para acceder a algunos suelos y las dificultades económicas paralizaron esta iniciativa municipal. A este movimiento inicial se sumaron otras iniciativas, tanto de carácter privado como público, constituyendo los años 2014-2015 el punto álgido en su desarrollo con 8 iniciativas, muchos de ellas vinculadas con la participación ciudadana en los movimientos del 15 y 22-M de 2014. Iniciativas que surgían con la ocupación de una parcela municipal en desuso y su posterior cesión municipal (Huertos la Dignidad y el Caminito). Tras una breve recesión, el movimiento se vuelve a reactivar en 2018 con tres nuevos huertos, algunos aún en fase de acondicionamiento (Figuras 7). 


\section{Figura 7. Evolución temporal de la creación de huertos urbanos}

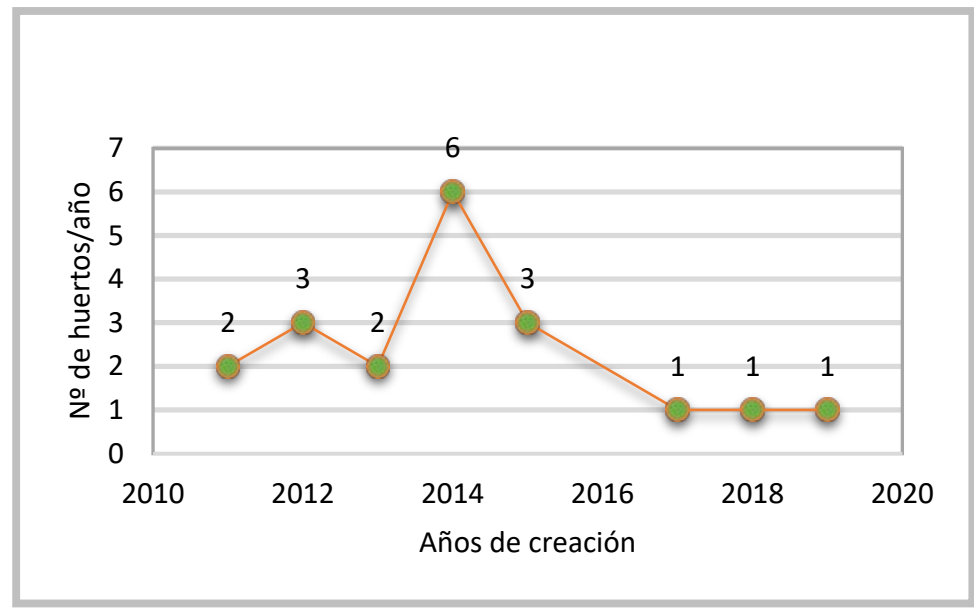

Fuente: elaboración propia

Loa huertos urbanos surgidos en la ciudad de Málaga responden a una amplia casuística, lo que impone la necesidad de llevar a cabo una clasificación de las distintas formas en las que éstos se manifiestan en la ciudad.

La tipificación ${ }^{4}$ de los huertos se ve dificultada desde el momento en que la finalidad originaria ha ido diversificándose con el paso del tiempo, añadiendo nuevos objetivos y motivaciones. En base a las características observadas en los huertos, la clasificación va a responder a tres criterios fundamentales: la titularidad (pública o privada), la gestión (municipal, autogestión, asociaciones, privada etc.) y la finalidad principal u originaria (ocio, terapéutica, docente/investigación, social, etc.).

Respecto a la titularidad (pública o privada) casi las 3/4 partes de los huertos $(73,6 \%$ ) son de carácter público, siendo al Ayuntamiento a quien pertenece el 42,1\% de los terrenos, cedidos a asociaciones de vecinos o a juntas de distritos, mientras que la Universidad y la Diputación aportan el 31,5\% de los solares. Los huertos privados en alquiler representan el 26,4\% restante, correspondiéndose fundamentalmente con los que aparecen en el distrito periurbano de Campanillas, donde se mezclan con la agricultura periurbana (Figura 8)

4 Las distintas tipologías de huertos urbanos desarrolladas atienden a criterios muy diversos, puesto que la mayoría de ellas son resultados de las evidencias empíricas de investigaciones desarrolladas en diferentes lugares y por tanto responden a los patrones existentes en cada caso de estudio. Una muestra de las existentes se puede consultar en las siguientes referencias bibliográficas: Arosemena, 2012; Busquets 2008; Ingersoll et al., 2007 ; Méndez et al., 2005, Muñoz, 2014; Puente, 2012. 
Figura 8. Clasificación de los huertos urbanos según su titularidad

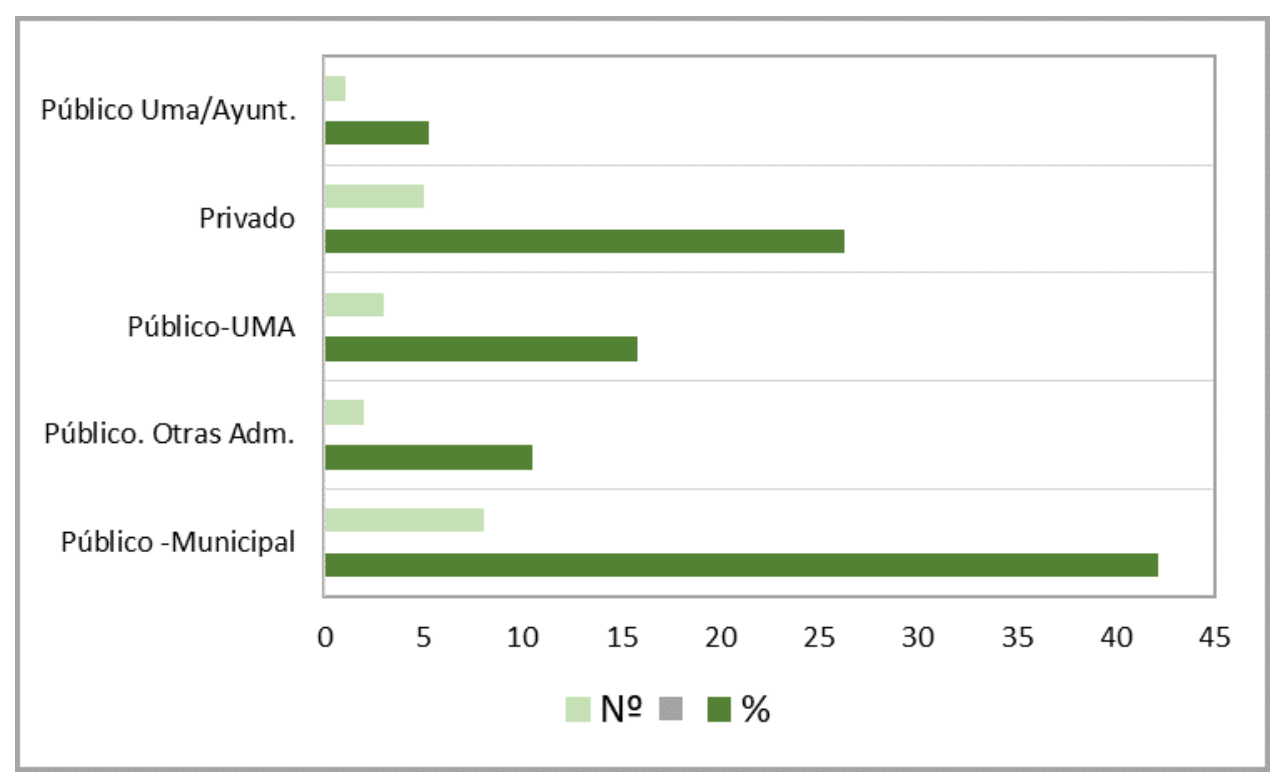

Fuente: elaboración propia

Los huertos urbanos son gestionados por 5 promotores diferentes (municipio, asociaciones, autogestionados, universidad, entidad privada), siendo las asociaciones las que gestionan más de las 2/3 partes, algunas formadas tras la creación del huerto (Asociación El Caminito, Jardín de Gamarra), otras previamente a su formación y con posterioridad se involucraron en la gestión y/o creación de los mismos (Huertum, Creahuertas, Ecoherencia). En segundo lugar, se sitúan los huertos gestionados por empresas privadas (26\%), a continuación, con una participación semejante se sitúan los huertos gestionados por la UMA y los autogestionados que se vinculan a los movimientos de las marchas por la Dignidad del 22-M (La Dignidad) y el movimiento 15-M (El Caminito), para terminar por los gestionados por el Ayuntamiento, a través de las junta de distrito (Moliere) o los servicios sociales (El Vergel de Málaga) (Figura 9).

Según su finalidad, algo más de la mitad de los huertos (58\%) surgieron con un carácter lúdico y social. ${ }^{5}$ No obstante, a esta motivación inicial se le ha ido añadiendo otras funciones que les conceden un perfil educativo, ocupacional y ambiental, al incorporar muchos de ellos cursos de formación para desempleados, actividades para la reinserción social (Huerta Jardín de Gamarra), talleres de agricultura ecológica, de reciclaje, festivales de economía sostenible (Huerto el Caminito) o visita de centros escolares y actividades de investigación (Huerto Moliere).

5 Entendiendo como social el deseo de compartir una actividad con sus vecinos, estrechar lazos y desarrollar actividades en comunidad. 


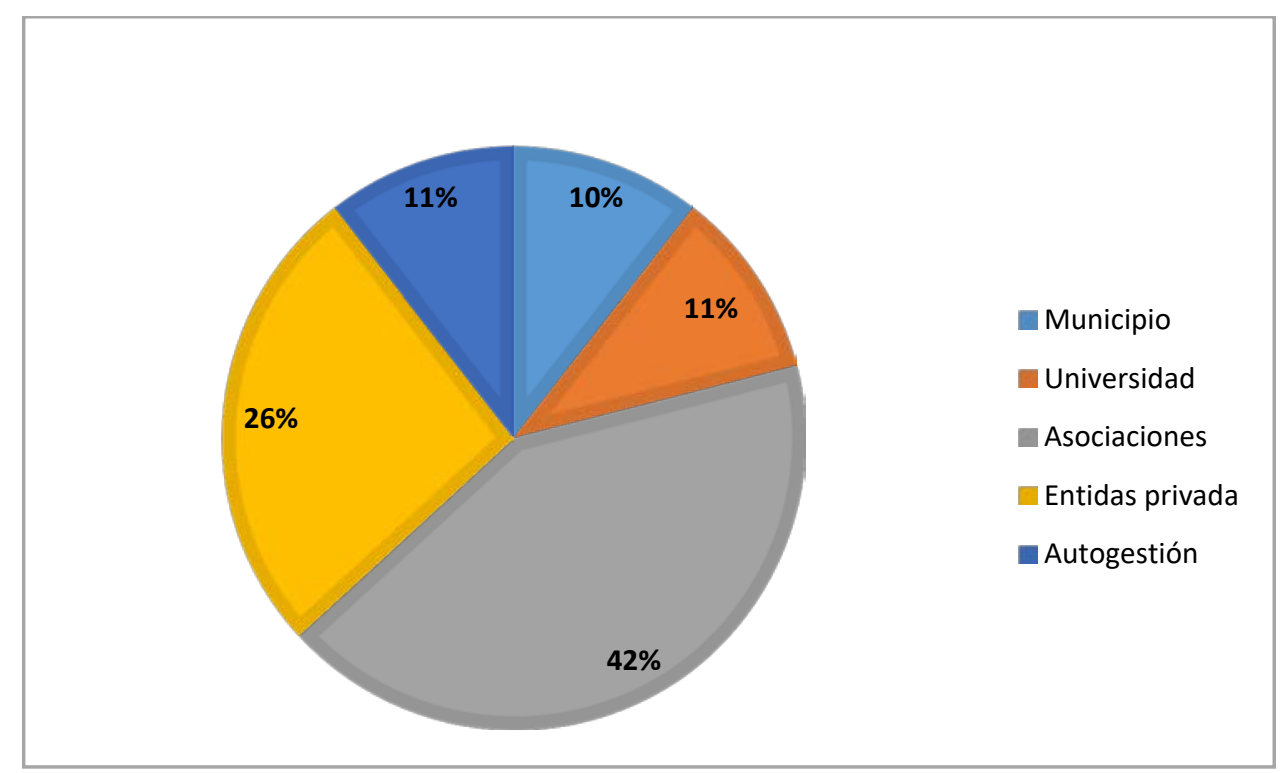

Fuente: elaboración propia

De la combinación de los tres criterios anteriores los huertos urbanos de Málaga, según aparecen en la Figura 10, se pueden clasificar en 6 tipos (comunitarios, municipales, formativosinvestigadores, terapéuticos, sociales, ocio-alquiler). De ellos, algo más de la mitad $(52,6)$ son huertos comunitarios y formativos-investigadores. Los huertos comunitarios son aquellos en los que su característica principal para ser clasificados como tales es ser gestionado bien por un grupo de vecino o una asociación con una identidad volcada en el huerto. Estas características corresponden a 5 huertos (El Caminito, Puerta de Málaga, La Dignidad, Jardín de Bailén y la Yuca) que con una vocación lúdica inicial han ido incluyendo con el paso del tiempo actividades ocupacionales, divulgativa y de investigación.

Cinco son también los huertos formativos-investigadores, gestionados bien por la Universidad (huerto docente de Ciencias, huerto urbano y parque frutal) o por asociaciones con una impronta ambiental (La Noria, J-Aulas Abiertas, Centro Scout medioambiental Vallejera). En este grupo se distinguen los estrictamente docentes como el huerto docente de la Facultad de Ciencias en el que participan alumnos de los Grados de Biología y Ciencias Ambientales con el objetivo de desarrollar habilidades y competencias transversales que no siempre se tratan en las asignaturas oficiales; y los huertos formativos-divulgativos que tratan de difundir prácticas agrícolas sostenibles y de concienciación medioambiental (La Noria, J-Aulas Abiertas, Vallejera, Huerto urbano y parque frutal de la UMA). En todos ellos está presente la investigación de especies autóctonas y de distintos métodos de cultivo. 
Figura 10. Tipología de los huertos urbanos

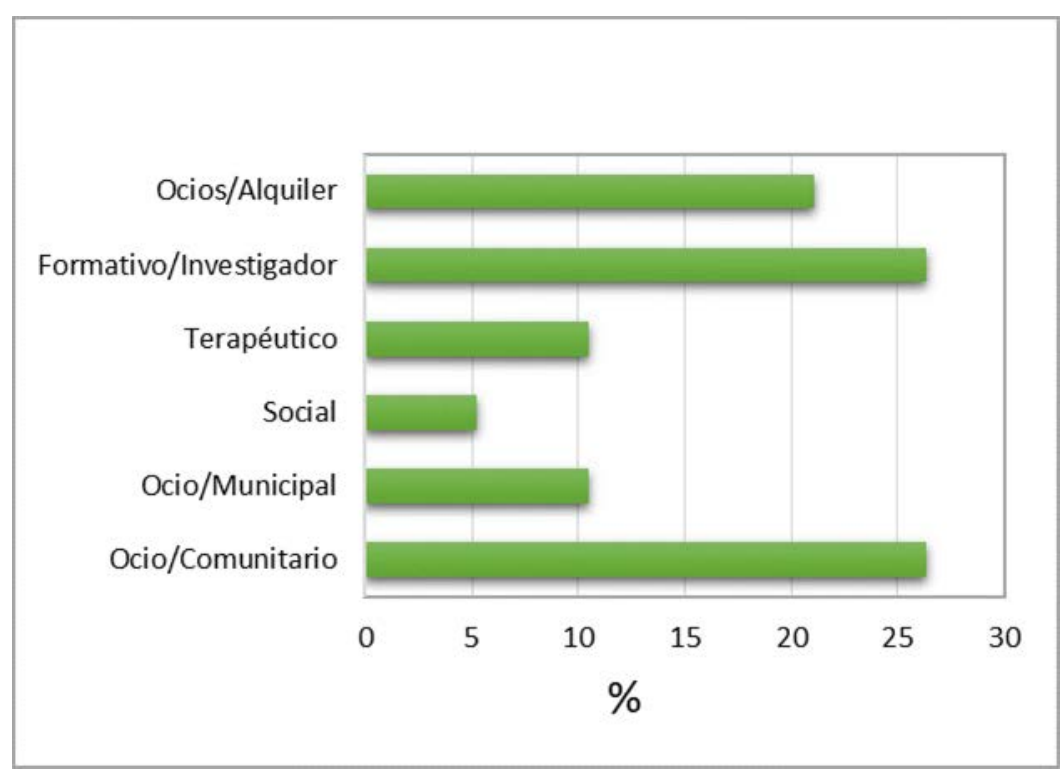

Fuente: elaboración propia

En tercer lugar, aparecen los huertos en alquiler $(21 \%)$ de carácter estrictamente privado. Son espacios acondicionados para el desempeño de labores agrícolas donde un usuario alquila un espacio de terreno con el fin de disfrutar de los productos que cultiva. Tres de estos huertos se ubican en el distrito de Campanillas (Püro Huerto, Rebanadilla, Llanos de Oliveros) y uno en el distrito Este (Huerta Tunesia). Los huertos en alquiler del distrito de Campanillas eran zonas ocupadas tradicionalmente por cultivos, principalmente cítricos, que debido a la caída de rentabilidad de los mismos, los propietarios han decidido reorientar la explotación y dividirla en parcelas para alquilar.

Los huertos municipales y terapéuticos suman otro $21 \%$. Los municipales también se ubican en terrenos de la administración, pero la diferencia con aquellos y la identidad de este tipo de huerto es que la administración se encarga de su mantenimiento y gestión, a través de la Junta municipal (Huerto Moliere) o los servicios sociales del distrito (Vergel de Málaga). Al igual que ocurre con los comunitarios a su finalidad primigenia de ocio se le ha añadido la ocupacionalsocial.

Los huertos terapéuticos, ubicados también en terrenos cedidos por la administración, bien el Ayuntamiento (Huertas Málaga) o la Diputación (Huerta Sensorial la Esperanza), suelen estar gestionado por asociaciones (Almunia y Asociación AFENES -Asociación de familias de personas con enfermedad mental- y APNAA -Asociación de padres de niños y adultos autistas-). El objetivo es revitalizar un área infrautilizada para atender a personas con minusvalías 
psíquicas, en cuyo proceso de creación participan activamente los usuarios, personal sanitario y familiares.

Por último, existe un huerto de carácter estrictamente social (La Píndola), gestionado por una asociación medioambiental (Huertum), al destinarse parte de los beneficios a funciones sociales a través de comedores sociales, mercadillos benéficos, ONG, para mejorar la situación de los más desfavorecidos y de personas en situación precaria.

\subsection{Características de los huertos y los hortelanos}

La superficie total ocupada por solares para huertos urbanos en Málaga asciende a $133275 \mathrm{~m}^{2}$ (13,3 hectáreas), estando el 40,69\% cultivada. Dentro de esta superficie la mayor extensión corresponde a los huertos formativos-investigadores debido al impulso que desde el Vicerrectorado de Smart-Campus se le está imprimiendo a la sostenibilidad urbana, seguida por la superficie ocupada por huertos privados en alquiler. Ambos tipos suman el 80,91\% de la superficie cultivada. En la superficie restante $(19,09 \%)$ son los huertos municipales con más de $7000 \mathrm{~m}^{2}$ de superficie cultivada (14,45\% de la superficie) los que alcanzan más significación (Tabla 3).

Tabla 3. Extensión superficial de los huertos y tamaño de las parcelas de cultivo

\begin{tabular}{|c|c|c|c|c|c|c|c|c|c|}
\hline \multirow[b]{2}{*}{ HUERTOS } & \multicolumn{2}{|c|}{ EXTENSIÓN } & \multirow[b]{2}{*}{$\begin{array}{l}\text { TIPOLOGÍA } \\
\text { DE HUERTOS }\end{array}$} & \multicolumn{3}{|c|}{ EXTENSIÓN } & \multirow[b]{2}{*}{$\begin{array}{c}N^{\circ} \\
\text { PARCE- } \\
\text { LAS }\end{array}$} & \multirow[b]{2}{*}{$\begin{array}{l}\text { TAM. } \\
\text { MEDIO } \\
\left(\mathrm{m}^{2}\right)\end{array}$} & \multirow[b]{2}{*}{$\begin{array}{c}\text { INVERSIÓN } \\
\text { MEDIA } \\
\text { (EUROS) }\end{array}$} \\
\hline & $\begin{array}{l}\text { Sup. } \\
\text { total } \\
\left(\mathrm{m}^{2}\right)\end{array}$ & $\begin{array}{c}\text { Sup. } \\
\text { cultivo } \\
\left(\mathrm{m}^{2}\right)\end{array}$ & & $\begin{array}{l}\text { Sup. } \\
\text { total } \\
\left(\mathrm{m}^{2}\right)\end{array}$ & $\begin{array}{c}\text { Sup. } \\
\text { cultivo } \\
\left(\mathrm{m}^{2}\right)\end{array}$ & $\%$ & & & \\
\hline \multirow{5}{*}{ Públicos } & \multirow{5}{*}{44412} & \multirow{5}{*}{13661} & Comunitarios & 12296 & 7150 & 58,14 & 240 & 20 & 43845 \\
\hline & & & Municipales & 4190 & 681 & 16,25 & 60 & 15 & 42500 \\
\hline & & & Terapéuticos & 1176 & 1000 & 8,03 & 21 & 14 & 53386 \\
\hline & & & Sociales & 2500 & 1500 & 60,0 & 120 & 20 & $s / d$ \\
\hline & & & Docente & 24250 & 3330 & 13,73 & 23 & 15 & 9000 \\
\hline Privados & 88863 & 40580 & En alquiler & 88863 & 40580 & 45,66 & 560 & 72.50 & 10000 \\
\hline Total & 133275 & 54241 & & 133275 & 54241 & & 1024 & 26.1 & 35094,3 \\
\hline
\end{tabular}

Fuente: elaboración propia a partir de Fernández (2012) \& Ayuntamiento de Málaga (2015)

La superficie cultivada está ocupada por 1024 parcelas $^{6}$ y son 1022 los usuarios, algo más de la mitad de las parcelas pertenecen a los huertos de carácter privado en alquiler, seguidos de los municipales y comunitarios con 300 parcelas (el 29,2\%). El número de parcelas por huertos oscilan entre 10 y 170, correspondiéndose estos extremos a los huertos de carácter privado. En

6 En la distribución parcelar de los huertos varias circunstancias hay que tener en cuenta: que algunos huertos de carácter público (municipales, formativos-investigadores) no están divididos en parcelas al ser de uso común entre todos los usuarios; por otro lado, algunos huertos de carácter público poseen algunas parcelas sin adjudicar y, por último, los huertos de carácter privado sólo se han contabilizado las parcelas en uso, pudiéndose ser su número mayor. 
los huertos de carácter público tanto el número de parcelas como su tamaño son superiores a los de carácter privado. En número de parcelas, los huertos públicos duplican ampliamente a los privados y en superficie los triplican (Tabla 3).

Para la puesta en funcionamiento, los huertos urbanos requieren un proceso previo de acondicionamiento, tanto si se trataba de solares abandonados o eran espacios con otra orientación. En los huertos públicos han sido el Ayuntamiento, la Diputación y la Universidad los organismos que se implicaron y subvencionaron el acondicionamiento de los huertos. En los de carácter privado, son los propietarios los que acondicionan los terrenos y crean la infraestructura necesaria para el cultivo.

Las actuaciones básicas comunes en las zonas de cultivo han sido: labores de desbroce, limpieza, nivelación de suelo, cerramiento, alumbrado, red de riego localizado, puntos de iluminación, organización y diseño de los bancales. Junto al espacio para el cultivo, los huertos disponen de un área complementaria compuesta por contenedor de barco reciclado o pequeñas casetas para depositar los aperos, una pérgola donde realizar reuniones y encuentros, espacio para jugar tanto los niños como los mayores (petanca) y, además, en los huertos privados espacios para barbacoas y cría de aves. Por último, el 90 \% de los huertos cuenta con semilleros y el $80 \%$ con compostera (Figura 11).

Figura 11. Planos de dos huertos urbanos

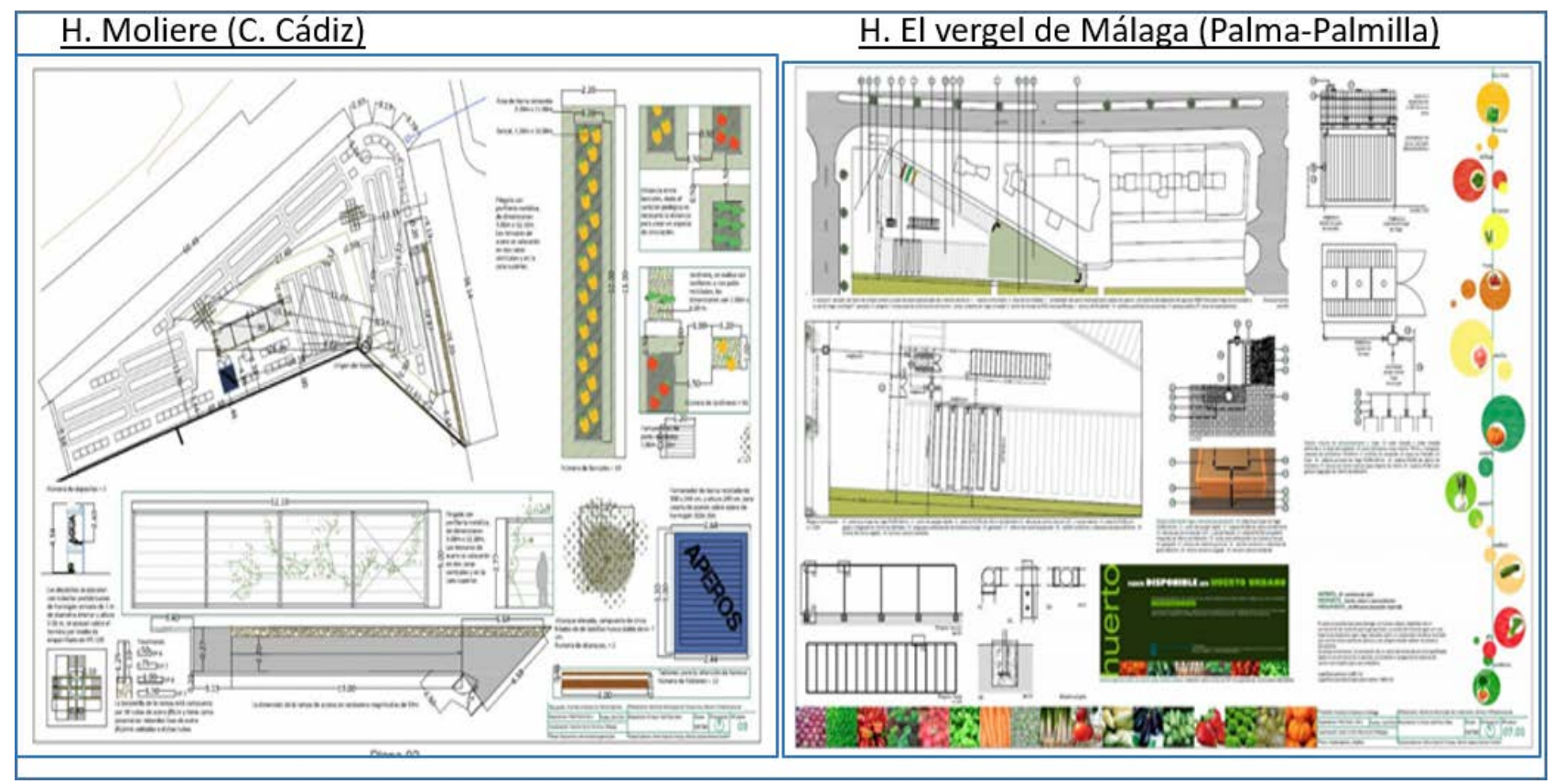

Fuente: Ayuntamiento de Málaga (2011) 
La inversión para la puesta en marcha y acondicionamiento de los huertos oscila entre los $12000 € /$ huerto en los privados a los $35000 € /$ huerto en los públicos (Tabla 2). Ello ha supuesto, en los huertos de carácter público, un coste unitario en torno a $5,5 € / \mathrm{m}^{2}$ para los huertos más pequeños (por debajo de los $500 \mathrm{~m}^{2}$ ) y de 15,43 para los de mayor tamaño por encima de los $1000 \mathrm{~m}^{2}$, diferencia que además de la extensión superficial, se debe a las características urbanas de partida, pues mientras los más pequeños estaban entre medianeras o exentos por tres lados y presentaba poca vegetación y residuo, los más grandes, en cambio, estaban totalmente exentos y con abundante vegetación (Fernández, 2013). Como una situación excepcional, hay que destacar el presupuesto para la instalación del huerto-frutal de la Universidad para lo que se ha comprometido en el presupuesto universitario de 2019, $1149500 €$, mientras que el gasto de las islas verdes terminadas ronda los $58000 €$ (UMA, 2019).

La edad de los hortelanos de los huertos oscila entre los 30 y 80 años (Figura 12). El grupo de edad más numeroso corresponde a edades adultas avanzadas y población vieja (el 60,72 \% de los hortelanos), ${ }^{7}$ mientras que en los estratos más jóvenes, entre 30 y 40 años, la participación baja hasta el 18,54\%, siendo meramente representativa los hortelanos por debajo de los 30 años y estos cuando aparecen se sitúan en los huertos en alquiler donde la media de edad es algo inferior a la de los públicos (el 86,9\% de los participantes tienen menos de 60 años). Es común la opinión que el huerto es una actividad poco interesante para los jóvenes de entre 18 y 30 años, debido a la existencia de otras formas de ocio; sin embargo, los hortelanos con hijos y nietos pequeños afirman que estos, una vez que los conocen, se interesan por la actividad.

En relación con el sexo, suele predominar el masculino en una proporción de 60 a 40, pero es significativo que en algunos huertos (La Yuca y Moliere) la participación de la mujer llega al $70 \%$.

En cuanto a la procedencia de los hortelanos, en los huertos públicos la inmensa mayoría pertenecen al lugar donde se sitúa el huerto o a los barrios aledaños, por lo que el tiempo invertido en el desplazamiento desde sus domicilios no es más de 15 minutos andando (Pérez et al., 2016). En cambio, el radio de influencia de los huertos privados en alquiler se extiende a toda la provincia. En estos no es frecuente la presencia de usuarios del entorno del huerto, puesto que al ser una zona periurbana los oriundos cuentan con su propio espacio de cultivo

7 Ello es así porque en la adjudicación de parcelas se ha primado a la población mayor de 55 años. 
tradicional. En este caso los hortelanos tardan en el desplazamiento entre 20 y 30 minutos en medio de locomoción.

Figura 12. Distribución de los hortelanos por grupos de edades

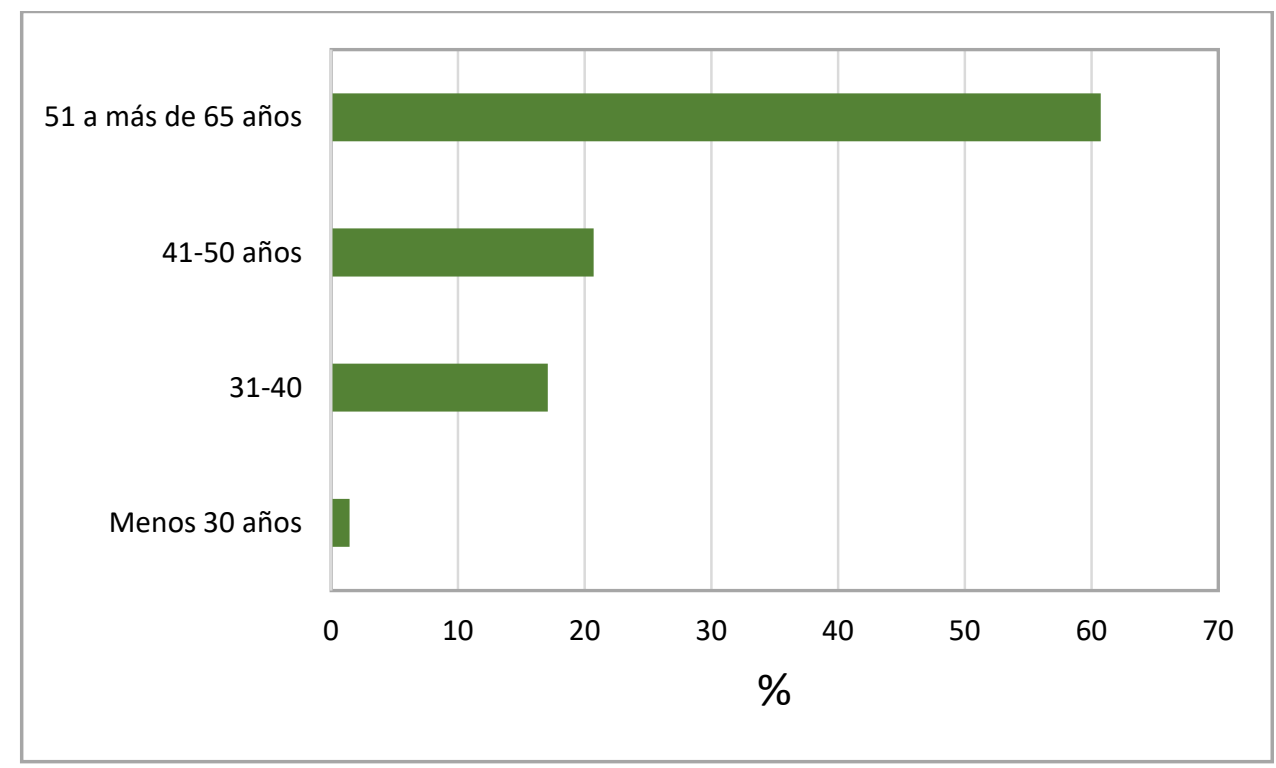

Fuente: elaboración propia

Respecto a la formación académica de los usuarios, la diversidad es la nota predominante. En los huertos municipales, en lógica relación con las características sociodemográficas de los barrios donde se insertan, predomina la población que no ha completado ningún ciclo formativo; en los huertos comunitarios la mezcla es mayor, aunque predomina la población que sólo tiene estudios básicos (La Yuca, La Noria); en algunos casos (Puerta de Málaga y Jardín de Bailén-Gamarra) se eleva el nivel formativo, de forma que en estos el 56,2\% de los hortelanos poseen estudios medios y universitarios. Igualmente en los huertos privados la presencia de población con formación superior a la básica es frecuente, habiendo en ocasiones población cursando estudios universitarios, siendo esta la población predominante en los huertos docentesinvestigadores.

La situación laboral en el momento de las entrevistas ponía de manifiesto que algo más de la mitad de la población era jubilada (54,2\%), seguida de la población en situación de paro (27,3\%); ello supone que más del 80 \% de la renta de los hortelanos procede de la pensión de jubilación, el subsidio de desempleo o ayudas sociales, sin obviar algunas actividades informales. En los huertos privados la población está más polarizada entre pensionistas y activos ocupados (Figura 13). 
Figura 13. Distribución de los hortelanos según su situación laboral

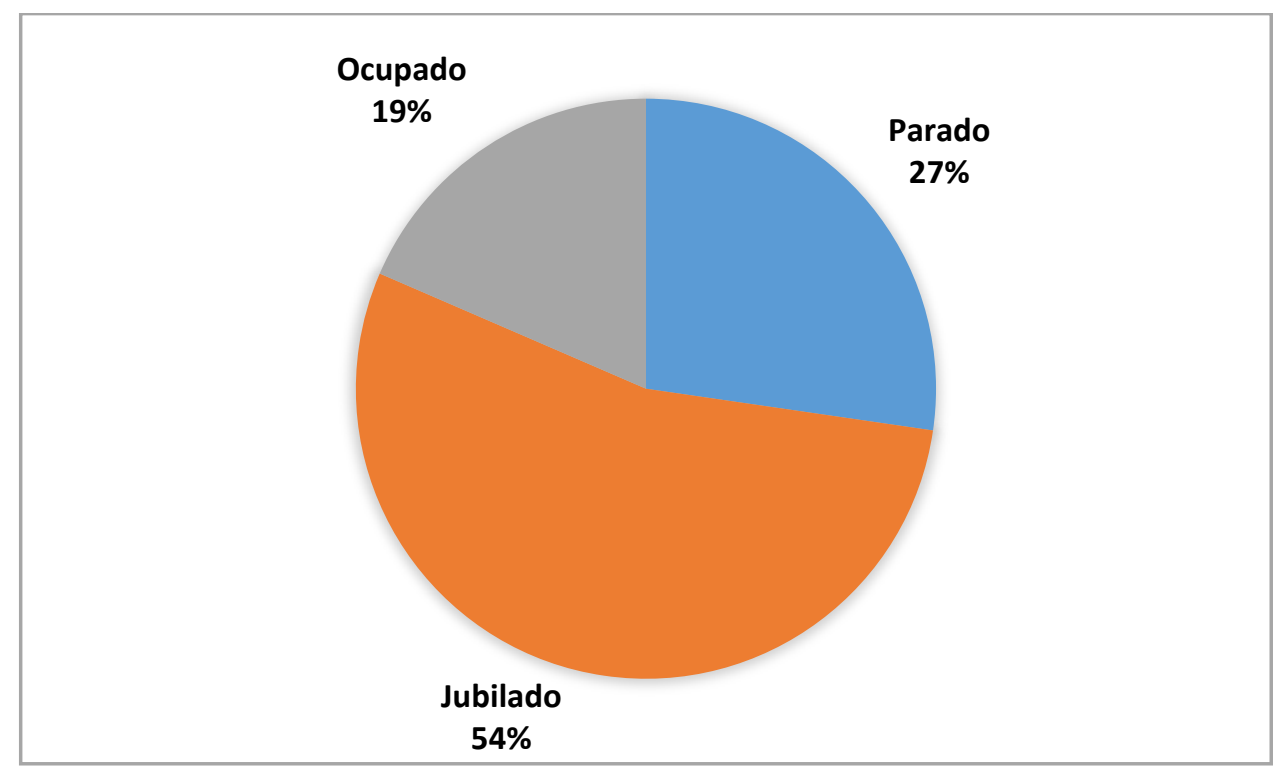

Fuente: elaboración propia

Respecto a la formación agrícola previa, el 73,9 \% de los usuarios no tenían conocimiento sobre agricultura o bien eran muy básicos. La mayor parte de los hortelanos han adquirido los conocimientos agrícolas tras acceder a la parcela. Los canales de aprendizaje han sido la experiencia, la observación directa en el propio huerto, la búsqueda de información en internet, la ayuda de familiares y amigos y, por último, cursos de formación impartidos, en algunos casos, por los promotores de los huertos. Es opinión generalizada que el cuidado del huerto no requiere conocimientos muy precisos, ni una larga preparación, sino tiempo y paciencia.

En el $70 \%$ de los casos las vías por las que los hortelanos conocieron la existencia de los huertos fueron el boca a boca, a través de otros vecinos o paseando por el barrio. A estas se les añaden las redes sociales y anuncios en distintos medios de comunicación, canal prioritario en los huertos en alquiler.

Entre las motivaciones más citadas para iniciarse en un proyecto de agricultura urbana destacan el ocio y el entretenimiento, la participación en un proyecto comunitario y razones medioambientales. Los hortelanos se mostraron, en general, muy satisfecho de participar en esta experiencia, señalando que los beneficios que les aportan los huertos son tanto a nivel individual como colectivo. Entre los primeros destacan el contacto con la naturaleza, disfrutar de una comida más sana y natural, la satisfacción personal, la evasión de los problemas cotidianos, el contacto con los demás, el disfrutar con la familia, ayuda económica, etc. Entre los beneficios 
colectivos señalan la recuperación de un espacio verde para el barrio, el compartir los productos con los vecinos, el despertar interés y curiosidad en el barrio por el medioambiente.

\subsection{Especies cultivadas y labores de cultivo: coste, producción y rendimientos}

Las normas de uso que establecen los huertos para ser cultivados no son muy restrictivas tan sólo que el sistema de cultivo sea ecológico, que los productos obtenidos se destinen al autoconsumo y que no se cultiven especies de gran porte, prohibiéndose en algunos casos el cultivo de especies arbóreas. El uso agrícola es el predominante en las parcelas que integran los huertos analizados, sólo en los de alquiler se dedica algún espacio a la cría de aves (principalmente gallinas). La gama de especies cultivadas es amplia y diversa aunque las variaciones anuales son muy limitadas, las que se producen entran dentro de las rotaciones de cultivo necesarias con el objeto de mantener la biodiversidad, el humus del suelo y el mejor aprovechamiento de los elementos nutritivos.

Son dos las cosechas que se obtienen a lo largo del año, la de otoño-invierno y la de primaveraverano, siendo esta última más abundante y diversa que la primera, hasta el punto que en la primera cosecha algunos huertos pueden estar infrautilizados, especialmente los que pertenecen a activos ocupados.

Las especies cultivadas en los 19 huertos urbanos inventariados se engloban en tres grandes tipos: en primer lugar se sitúan la superficie ocupada por los cultivos tradicionales de huerta mediterránea (90\%), optando por las especies más fáciles de cultivar y de obtención de semillas. Aunque en ellos, la gama de especie es amplia, sin embargo, el $80 \%$ de la superficie se ocupa con aquellas que se consideran hortalizas básicas de consumo. En otoño-invierno suele predominar las hortalizas de hojas (col, acelgas, espinacas, habas, guisantes, alcachofas, etc.) de crecimiento más rápido y más resistentes a las temperaturas más bajas que las hortalizas de raíces; entre las de primavera-verano predominan las de frutos y vaina (pimiento, tomate, berenjena, judías verdes, etc.), a las que hay que añadir las de continuidad (zanahoria, lechugas, patatas, etc.). Tal y como se aprecia en la figura 14 ello permite un abastecimiento continuado de productos durante todo el año.

El segundo grupo de especies cultivadas son las plantas aromáticas y medicinales, que también aparecen bajo un amplio espectro, pero en superficies muy reducidas, exceptuando aquellos huertos que presentan una función más paisajística y medioambiental (Jardín de Bailén-Miraflores y La Yuca) donde ocupan casi un tercio del espacio. Suelen ser plantas que se intercalan entre los cultivos principales o colonizan las lindes de las parcelas. Son especies imprescindibles en el 
huerto ecológico, no sólo porque son fáciles de cultivar, no muy exigentes en cuanto a riego y sustratos, sino por su papel en repeler las plagas (lavanda, tomillo, borraja, consuelda, hinojo, romero, albahaca, siempreviva, etc.), o en la polinización (capuchina, ajedrea, caléndula, cola de caballo, salvia, etc.).

Figura 14. Calendario de siembra y consumo de las principales especies hortícolas cultivadas

\begin{tabular}{|c|c|c|c|c|c|c|c|c|c|c|c|c|}
\hline Especies & En & Feb & Maz & Abr & May & Jun & Jul & $\mathrm{Ag}$ & Sep & Oct & Nov & Dic \\
\hline \multicolumn{13}{|c|}{ Hortalizas de Invierno } \\
\hline Guisante & & & & & & & & & 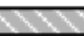 & W & $\infty$ & \\
\hline Haba & & & & & & & & & & & (- & \\
\hline \multicolumn{13}{|c|}{$\rightarrow \infty$} \\
\hline Alcachofa & & & & E. & (a) & 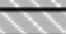 & & & & & \multirow{3}{*}{\multicolumn{2}{|c|}{ 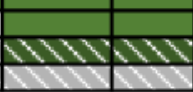 }} \\
\hline Acelga & $x^{2}=$ & $k \times x^{2}$ & mors & & & & & & (n) & (a) & & \\
\hline \multicolumn{11}{|c|}{ 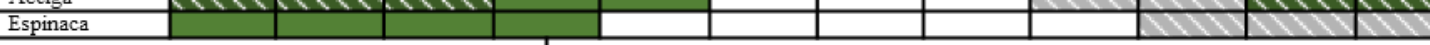 } & & \\
\hline \multicolumn{13}{|c|}{ Hortalizas de Continuidad } \\
\hline \multicolumn{13}{|c|}{ Zanahoria $=1 / \mathrm{M} / \mathrm{M}$} \\
\hline \multirow{2}{*}{\multicolumn{13}{|c|}{$\begin{array}{l}\text { Cebolla } \\
\text { Ajo }\end{array}$}} \\
\hline & & & & & & & & & & & & \\
\hline \multicolumn{13}{|l|}{ Patata } \\
\hline Lechuga & & & & & & & & & & & & 17 \\
\hline Hortalizas & Vera & & & & & & & & & & & \\
\hline \multicolumn{13}{|l|}{ Berenjena } \\
\hline \multicolumn{13}{|l|}{ Calabacin } \\
\hline \multirow{2}{*}{\multicolumn{13}{|c|}{$\begin{array}{l}\text { Judia } \\
\text { Melón }\end{array}$}} \\
\hline & & & & & 5 & a & & & & & & \\
\hline \multicolumn{13}{|c|}{$m$} \\
\hline \multicolumn{13}{|l|}{ Tomate } \\
\hline Pimiento & & & & & & & & & & & & \\
\hline \multirow{2}{*}{\multicolumn{13}{|c|}{$\begin{array}{l}\text { Pepino } \\
\text { Fresa }\end{array}$}} \\
\hline & & & & & & & & & & & & \\
\hline & \multicolumn{4}{|c|}{ Período de siembra } & & & & & & & & \\
\hline & \multicolumn{4}{|c|}{ Período de consumo } & & & & & & & & \\
\hline
\end{tabular}

Fuente: elaboración propia

En tercer lugar, hay que citar la recuperación de especies autóctonas y otras que no son habituales en los canales de comercialización actuales, como son el alficoz, el cucamelón, el chacote (pertenecientes a la familia de las curbubitáceas), el kale (un tipo de col rizada), el aguaturma (tubérculo), la verdolaga (familia portulacaceae) y ocra (familia de las malváceas). Estas especies suelen aparecer prioritariamente en aquellos huertos promovidos por centros de educación ambiental, dado que sus objetivos principales son educativos y de promoción de prácticas agrícolas y ecológicas. En ellos se investiga la adaptación de estas especies al entorno y las posibilidades de asociación con otros cultivos. ${ }^{8}$

La biodiversidad de los huertos urbanos se explica mayormente por la alta variedad de especies cultivadas que por la utilización de muchos cultivares de pocas especies. Ello responde a dos

8 La combinación de verdolaga y ocra con hortalizas tradicionales es una de las combinaciones que se están investigando en la huerta "La Noria". 
motivos interrelacionados: la pequeña superficie de los huertos y el deseo de adaptar la producción a las necesidades familiares, controlando los excedentes y extrayendo el máximo beneficio para la economía familiar. No obstante, en los picos de producción, son inevitables los excedentes que se intercambian por otras especies con los restantes hortelanos del huerto o se distribuyen entre familiares, amigos y vecinos. La producción de los huertos suele pertenecer al hortelano que lo cultiva, salvo en los huertos comunitarios (La Yuca y Moliere) que se reparte de forma colectiva, al igual que en los huertos docentes/investigadores, mientras que en el huerto de carácter social (La Píndola) una parte de la cosecha se destina para cubrir las necesidades de distintos grupos de población.

En cuanto a las labores de cultivo, el huerto implica una actividad no muy intensa pero sí continuada durante todo el año. Las labores fundamentales en cada cosecha son labrar, abonar, sembrar, regar, desbrozar malas hierbas, el entutorado de plantas trepadoras y la recolección, amén de aquellos huertos que tienen semilleros y composteras que requieren un cuidado añadido.

La preparación del terreno se inicia un mes antes de la siembra (febrero-marzo y septiembreoctubre, según campaña) con la eliminación de la vegetación superficial y el laboreo de la tierra para dejarla suelta, mullida y oxigenada, labores que se realizan de forma manual (azada, rastrillo) o con motoazada. ${ }^{9}$

Seguidamente se procede al abonado. Aunque la mayoría de huertos tienen composteras y los huertos urbanos tratan de cumplir los principios de la agricultura ecológica, muy pocos son los que utilizan para fertilizar el abono realizado por ellos mismos (abono en verde o compost) incluso, en caso de realizar el compost, sólo constituye una ayuda al no producirse el suficiente para cubrir el total de las necesidades del huerto, por lo que suele ser habitual su adquisición externa. El abonado orgánico suele proceder de explotaciones de ganado de conocidos y se suele adquirir de forma colectiva, siendo a veces regalado. Se incorpora dos veces al año antes de cada cosecha, a excepción de algunos huertos donde la mala calidad de la tierra (Huerto Moliere) aconseja su incorporación dos veces por campaña de cultivo, o los huertos docentesinvestigadores que incorporan con más frecuencia humus de lombriz proveniente de la compostera.

9 El $90 \%$ de las labores de cultivo las realiza el hortelano que está al frente del huerto, sólo en momentos puntuales cuenta con ayuda de familiares y amigos. 
Tras el abonado se procede a la siembra. Al igual que ocurre con el abonado, aunque la mayor parte de los huertos poseen semilleros, en más del 80 \% de los casos las semillas son de origen comercial. La compra externa en viveros incrementa el uso de plantones frente al de semilla, puesto que se reduce el tiempo de entrada en producción.

La falta de experiencia y de formación de los usuarios, para lo que tienen en contra el poco tiempo que llevan cultivando el huerto, ${ }^{10}$ la mayoría no más de cuatro años, así como no haber trabajado ni tenido con anterioridad contacto con aspectos relacionados con la agricultura, condicionan la actividad en el huerto, en especial una correcta rotación de cultivos, la lucha contra plagas y enfermedades, y aspectos como que las semillas, abonos, etc. sean mayoritariamente de origen comercial. Los hortelanos al respecto reconocen su debilidad, son conscientes que requerirían mayor formación que la que adquieren a través de libros, internet, o aprendiendo directamente de los hortelanos que más conocimientos poseen.

Finalmente, están las labores de mantenimiento del huerto, una de las principales es el riego, clave para el éxito de la cosecha, este depende de las características del suelo, de las necesidades hídricas de cada especie y de la época del año. La norma general es aportar de 1 a 2 riegos por semanas en invierno, siempre que no llueva, mientras que en verano asciende a 3-4 por semana ${ }^{11}$. En los huertos de docencia e investigación se incorpora 6 riegos al día de 10 minutos cada uno. El sistema de riego en el 95\% de los huertos es localizado, por goteo.

Otra labor de continuidad y decisiva para el buen resultado de la cosecha es la lucha contra plagas y enfermedades que si se desarrollan las medias preventivas necesarias (abonado, siembra, riego, etc.) no tiene por qué constituir un problema grave, pero la falta de experiencia, tiempo y formación, como venimos indicando, aparecen como hándicaps. Los tratamientos fungicidas que se utilizan tienen distintas procedencias: por un lado, los de uso comercial permitido en agricultura ecológica, como el azufre y el cobre, aunque para este último la UE tiene limitando su uso. Por otro lado, los preparados naturales realizados por los propios hortelanos constituyen el método más generalizado (jabón potásico). Por último, uno de los métodos más eficaces y viable es la lucha integral contra las plagas, utilizando distintos métodos, entre ellos, una buena asociación de cultivo, uso de variedades locales, rotación de cultivos adecuadas y el uso de plantas beneficiosas en el huerto que atraigan insectos beneficiosos o

10 El período de disfrute en los huertos públicos es de 2 a 4 años, en los privados es ilimitado.

11 Ello condiciona las visitas al huerto, de forma que en invierno suelen ser de 2 a 3 días/ semana, con una dedicación de 2 a 3 horas/día y, en verano de 4 a 5 días/semana con una dedicación media de 4 horas. 
que ahuyenten a pulgones, mosca blanca y otras plagas. No obstante, los resultados de esta técnica vuelven a estar condicionados por la formación del hortelano y la falta de personal cualificado que lo pueda instruir.

Con el aclareo o entresacado, el enturorado (tomates y judías), el desbroce (tomates) y el control de malas hierbas de forma manual con la escarda se completa las labores de cultivo. A estas hay que añadir algunas labores colectivas para el mantenimiento de las zonas comunes para el ocio.

Aunque los huertos urbanos funcionan en un marco social ajeno al mercado, debido tanto a la pequeña escala de lo producido como a la voluntad prioritaria de producir relaciones comunitarias, no obstante, no hay que obviarlos y se pueden valorar desde dos perspectivas: por un lado, lo que supone el valor de los insumos que se les proporciona al huerto y, por otro lado, cómo repercute lo producido en la economía familiar.

Respecto al primer aspecto hay que hacer notar que el gasto invertido para el cultivo varía en función de la adquisición de los insumos, en el mercado o fuera de él, y de las labores de cultivo aportadas. En general, el gasto en insumos en los huertos oscila entre 133 y $166 €$ anuales según sean públicos o privados, pudiendo bajar de los $100 €$ si no se incluyen algunos inputs (sustrato), o ser puramente testimonial cuando algunos insumos son obsequiados (semillas, abonos) o de elaboración casera (fitosanitarios). Esta inversión se eleva a $157 €$ en el caso de los huertos públicos con el pago de la cuota anual de mantenimiento y supera los $500 €$ en los huertos en alquiler (Tabla 4). La mayoría de los hortelanos perciben estos gastos como aceptables y como dinero bien invertido en relación al ahorro que la cosecha supone en la cesta de la compra y sobre todo por la calidad de los productos obtenidos.

El segundo aspecto está relacionado con el ahorro que puede suponer la producción del huerto en la economía familiar. Hay que partir de la base que la productividad de los huertos urbanos es limitada, se trata de una producción contenida a lo largo de los años, incluso en descenso algunas campañas. Los problemas que presentan los huertos en su manejo asociados principalmente a la mala calidad y profundidad del suelo, la baja polinización, la laxa aplicación de las prácticas culturales son razones que inciden negativamente en la productividad. No obstante, los hortelanos dan por bueno los resultados, porque una producción excesiva constituiría un despilfarro de los recursos invertidos al sobrepasar las necesidades de consumo familiar. 
Tabla 4. Coste económico en un huerto de tamaño medio

\begin{tabular}{|c|c|c|c|}
\hline INSUMOS & CANTIDAD Y PRECIO MEDIO & $\begin{array}{l}\text { HUERTO } \\
\text { PÚBLICO } \\
(€) \\
\left(20 \mathrm{~m}^{2}\right)\end{array}$ & $\begin{array}{l}\text { HUERTO } \\
\text { PRIVADO } \\
€ \\
\left(60 \mathrm{~m}^{2}\right)\end{array}$ \\
\hline Semillas/Plantones & $0,15-0,20 \in$ & 37 & 70 \\
\hline Abono & $\begin{array}{c}\text { Abono orgánico } \\
\text { (caballo, humus lombriz): } 15 \mathrm{~kg} / 9 € \\
\text { Abono orgánico comercial: } 25 \mathrm{~kg} / 15 €\end{array}$ & 36 & 56 \\
\hline $\begin{array}{l}\text { Control de plagas } \\
\text { (azufres, cobre, } \\
\text { jabón potásico) }\end{array}$ & $\begin{array}{c}\text { Azufre: } 4,25 € / \mathrm{kg} \\
\text { Cobre: } 2,60 € / \mathrm{kg} \\
\text { Jabón potásico: } 6,68 € / 5 \mathrm{~kg}\end{array}$ & 15 & 25 \\
\hline Sustrato & $7 € / 20 \mathrm{~kg}$ & 40 & - \\
\hline $\begin{array}{l}\text { Otros (tutores y } \\
\text { ataduras, etc.) }\end{array}$ & $23 \in / 1000$ unidades & 5 & 15 \\
\hline Total & & 133 & 166 \\
\hline Cuota anual & $2-3 € /$ mes a $35 € /$ mes & 157 & 586 \\
\hline
\end{tabular}

Fuente: elaboración propia

Para obtener el máximo beneficio económico del huerto, uno de los aspectos fundamentales es la planificación. Una planificación que debe ser integral; por un lado, valorando las posibilidades que este ofrece y adaptando su diseño al entorno; por otro lado, realizar una planificación de los cultivos en función de las necesidades y hábitos alimenticios de los hogares. Asimismo, hay que tener en cuenta el precio del producto en el mercado, pues si este es bajo y la especie es difícil de cultivar no compensa el esfuerzo invertido, por el contrario es un acierto aquellas que son más caras en el mercado y fáciles de cultivar.

Para valorar de forma general lo que supone el cultivo de hortalizas en la cesta de la compra familiar se ha elaborado la Tabla 5 que incluye un cómputo de la producción media de hortalizas por $\mathrm{m}^{2}$, el consumo medio de hortalizas per cápita en España ${ }^{12}$ y por tamaño medio familiar (3 miembros adultos) ${ }^{13}$, la superficie necesaria para cubrir las necesidades familiares y el precio medio de mercado.

12 El consumo per cápita de hortaliza fresca y patatas en España en el año 2018 ha sido de 94,68 kg por persona y año.

13 Se ha considerado una familia de tres miembros adultos porque el consumo de hortalizas varía en función de la composición de los hogares, en general la presencia de niños supone un menor consumo per cápita de hortalizas, por ejemplo en los hogares sin niños se alcanzan un consumo de 81 kg per cápita, mientras que en los hogares con niños entre 6 y 15 años apenas si llega a los 39 kg por personas (Martín, 2015). 
Tabla 5. Producción de hortalizas en el huerto, consumo per cápita y gasto familiar $(€)$

\begin{tabular}{|c|c|c|c|c|c|c|}
\hline ESPECIES & $\begin{array}{c}\text { CONSUMO/ } \\
\text { PER CÁPITA } \\
(\mathrm{Kg})\end{array}$ & $\begin{array}{c}\text { CONSUMO } \\
\text { FAMILIAR (3 } \\
\text { MIEMBROS) } \\
(\mathrm{Kg})\end{array}$ & $\begin{array}{c}\text { PRODUCCIÓN } \\
\left(\mathrm{Kg} / \mathrm{m}^{2}\right)\end{array}$ & $\begin{array}{c}\mathrm{m}^{2} \\
\text { NECESARIOS }\end{array}$ & $\begin{array}{l}\text { PRECIO } \\
\text { MEDIO } \\
(€ / \mathrm{Kg})\end{array}$ & $\begin{array}{c}\text { GASTO } \\
\text { FAMILIAR } \\
(€)\end{array}$ \\
\hline \multicolumn{7}{|c|}{ Hortalizas de frutos y flores } \\
\hline Tomate & 13,26 & 39,6 & 7,5 & 5,2 & 1,60 & 63,3 \\
\hline Pimiento & 4,36 & 13,08 & 3,4 & 3,8 & 1,84 & 24,06 \\
\hline Calabacín & 3,25 & 9,75 & 3,7 & 2,6 & 1,38 & 13,45 \\
\hline Pepino & 2,1 & 6,3 & 2,8 & 2,2 & 1,77 & 11,15 \\
\hline Fresas & 2,4 & 7,2 & 2 & 3,6 & 2,75 & 19,8 \\
\hline Sandias/melones & 16 & 48 & 6,5 & 7,3 & 0,92 & 44,16 \\
\hline Berenjenas & 0,8 & 2,4 & 2,8 & 0,5 & 1,59 & 3,80 \\
\hline Alcachofa & 1,6 & 4,8 & 2,5 & 1,9 & 2,39 & 11,47 \\
\hline Total & 43,37 & 131,13 & 31,20 & 27,10 & 1,78 & 233.4 \\
\hline \multicolumn{7}{|c|}{ Hortalizas de hojas, tallos tiernos y vaina } \\
\hline J. verdes & 2,0 & 6 & 2,0 & 3,0 & 3,75 & 22,50 \\
\hline Lechuga & 2,84 & 8,5 & 3,0 & 2,8 & 2,82 & 23,97 \\
\hline Acelga & 4 & 12 & 6,0 & 2,0 & 1,95 & 23,40 \\
\hline Col & 1,3 & 3,9 & 4,0 & 0,9 & 1,22 & 4,75 \\
\hline Guisantes & 2,2 & 6,6 & 0,8 & 8,2 & 1,22 & 23,10 \\
\hline Habas & 0,5 & 1,5 & 0,9 & 1,6 & 1,5 & 1,80 \\
\hline Total & 12,84 & 38,5 & 16,7 & 18,5 & 2,07 & 79,69 \\
\hline \multicolumn{7}{|c|}{ Hortalizas de raíces, bulbos y Tubérculos } \\
\hline Cebolla & 6,6 & 19,9 & 5,0 & 3,9 & 1,10 & 21,89 \\
\hline Rábano & 0,3 & 0,9 & 4,0 & 0,2 & 0,50 & 0,45 \\
\hline Zanahoria & 3,3 & 9,9 & 4,0 & 2,4 & 1,02 & 10,09 \\
\hline Patała & 19,71 & 59,1 & 5,0 & 11,8 & 0,77 & 45,50 \\
\hline Ajo & 0,8 & 2,4 & 1,5 & 1,6 & 3,50 & 12,69 \\
\hline Total & 30,71 & 92,2 & 19,5 & 19,9 & 1,37 & 126,3 \\
\hline Total & 87,3 & 261,8 & 67,4 & 65,5 & 1,74 & 439,4 \\
\hline
\end{tabular}

Fuente: elaboración propia a partir

de Ministerio de Agricultura pesca y alimentación (2019) \& COAG (2018)

El abanico de hortalizas y tubérculos que se cultiva en los huertos de la capital supone un consumo per cápita de $87,3 \mathrm{~kg}(261,9 \mathrm{~kg}$ el familiar), de ellas, al igual que ocurre a nivel nacional, ${ }^{14}$ es el consumo de hortalizas de frutos y flores el mayoritario $(50,08)$, y el que más gasto genera (46\%); a continuación se sitúa en cuanto al consumo las hortalizas de raíces, bulbos y tubérculos $(92,2 \mathrm{~kg} /$ familia), aunque por su valor es el grupo que menos inciden en el gasto familiar en hortalizas (16,41\%); por último en el grupo de hortalizas de hojas, tallos y vaina, aunque es el de menor consumo (12,72\%), su valor económico lo sitúa en segundo lugar (26\%) (Figura 15).

14 En España casi el $50 \%$ de los kilos consumidos corresponden a las hortalizas de los grupos de frutos y flores, que supone el $43 \%$ de la facturación de verduras y hortalizas; seguidas por las de raíces, bulbos y tubérculos (con un valor del $13,6 \%$ y un consumo del 19,6\%), mientras que las de hojas, tallos y vainas suponen el 12,9\% del consumo, con un valor del 19,3\% (MAPA, 2019). 


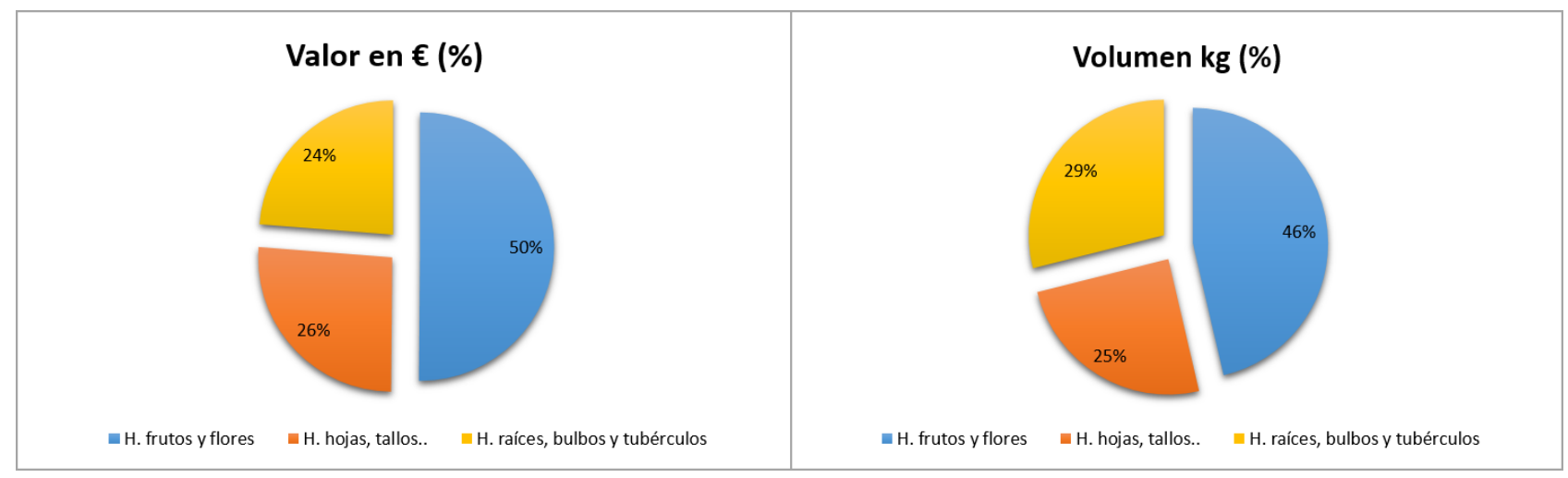

Fuente: elaboración propia

Para que el horticultor pueda asegurar el consumo total de hortalizas a través del cultivo de su huerto tendría que contar con una extensión de $65,5 \mathrm{~m}^{2}$, lo que le supondría un ahorro de $439,4 €$ anuales sin contemplar los gastos de cultivo. Si consideramos que el coste medio de la cesta de la compra en España, según el INE en 2017, fue de 4986 euros, ello supondría un ahorro del $8,8 \%{ }^{15}$ Si bien esta no es una realidad que se pueda generalizar para el conjunto de los huertos urbanos malagueños, puesto que el tamaño medio de la parcela en los huertos de carácter público es 2,3 veces inferior a la necesaria, de esta forma, el ahorro se situaría en torno al $4 \%$, aunque si tenemos en cuenta que las hortalizas que más se siembran y que constituyen el grueso del consumo son las hortalizas de frutos y flores sí que cubriría ampliamente las necesidades familiares prioritarias. En los huertos en alquiler, en cambio, sí se cubriría el abastecimiento familiar completo en este capítulo alimenticio al ser el tamaño medio del huerto superior al necesario $\left(72,5 \mathrm{~m}^{2}\right)$.

\section{Conclusiones}

El interés del municipio de Málaga por el desarrollo de los huertos urbanos se ha centrado en el desarrollo de un amplio espectro de asociaciones, organizaciones, iniciativas y proyectos que apoyan esta actividad, así como la dedicación de suelo para la instalación de huertos para todos los colectivos sociales y edades. Con anterioridad a la crisis económica de 2008 no existían en la ciudad ninguna iniciativa en este sentido, ha sido con posterioridad al estallido de la burbuja inmobiliaria y tras los acontecimientos de marzo de 2014 ("marchas por la dignidad") cuando el

15 Según el Informe del consumo alimentario en España (MAPA, 2019), el volumen medio de hortalizas y patatas en la cesta de la compra de los españoles gira en torno al 12,5\% anual, ello supone que los hogares destinan a este capítulo el 9,33\% del presupuesto destinado a la compra de alimentación bebidas. 
interés por los huertos urbanos se ha manifestado tanto por parte de las diferentes administraciones (Ayuntamiento, Diputación, Universidad), como por la propia sociedad civil (Asociaciones vecinales), en la misma línea que ha ocurrido en muchas ciudades españolas y europeas, como lo pone de manifiesto diversos estudios (Ballesteros, 2018; Partalidou, 2017; Espinosa, 2017; Fantini, 2016).

En las últimas décadas, y con muy pocas excepciones, la urbanización ha supuesto una gran presión sobre las ciudades, tanto en las de los países pobres y emergentes como en las de los desarrollados (Fantini, 2016). Ante ello, como se pone de manifiesto en múltiples investigaciones (Colding et al., 2013; Aguglia el al., 2009) y por diversos organismos internacionales (FAO, OCDE), la agricultura se presenta como un elemento de transformación multidimensional desde el momento en que el impacto sobre el bienestar social no se limita únicamente a la producción de alimentos, sino que desempeña otras muchas funciones para el equilibrio ambiental, social, económico, etc. En este contexto la agricultura urbana surge como un elemento de transformación multidimensional.

A lo largo del trabajo se ha podido constatar el objetivo de partida y es que en la ciudad de Málaga, la agricultura urbana se presenta como una alternativa de transformación urbana tanto desde el punto de vista territorial, social y económica y a través de sus diferentes tipología ha sido capaz de adaptarse a un amplio espectro de realidades socioeconómicas diferentes. Para ello ha sido fundamental evidenciar, además de sus peculiaridades técnicas (manejo del terreno, técnicas, cultivos, etc.) (Mougeot, 2005, 2006; Orsini et al., 2013) y funciones ecoambientales (Mougeot, 2006; Lovell, 2010), la importancia de sus elementos sociales (participación ciudadana, generación de asociaciones). No cabe duda que estos aspectos están presentes en los diferentes huertos urbanos que se han desarrollado en la ciudad, desde el momento en que han supuesto una alternativa sostenible válida, por un lado, para dar un fin útil a aquellos solares en desuso o parcelas abandonadas y, por otro lado, para constituir una respuesta económica, social y medioambiental en una sociedad que tiene planteados distintos retos como puede ser la restauración ecológica, la nutrición y la salud, la seguridad alimentaria, la educación ambiental, la participación ciudadana, etc.

La agricultura urbana por su carácter polifuncional, como herramienta de definición de muchos espacios urbanos y dada la diversas tipologías implementadas ha tenido en la ciudad implicaciones positivas desde distintos puntos de vistas (social, medioambiental y económico), pero también ha puesto de manifiesto algunas carencias que se requeriría atender para que la 
estrategia de los huertos sea un verdadero instrumento que colabore en la rehabilitación urbana ecológica y en el fortalecimiento e integración social y valores comunitarios.

Respecto a los aspectos positivos se ha podido constatar que los huertos más allá del hecho inédito de que sean espacios públicos cultivables, cuando funcionan bien, son espacios polivalentes donde se intensifican las relaciones sociales. En estos espacios se tejen importantes redes sociales entre sus usuarios/beneficiarios, que oscilan desde las puramente laborales (colaboración en la plantación, tratamiento y recolección de productos) a lazos de amistad más intensos que se proyectan fuera de estos espacios. En esta línea, un aspecto importante a destacar es que han generado movimientos asociativos, siendo una herramienta para sensibilizar a la ciudadanía sobre problemas relacionados con la sostenibilidad, el intercambio, producción de conocimientos y conseguir mayores cuotas de empoderamiento social, económico, aspectos que han sido confirmado empíricamente por diversos investigadores (Fantini, 2016; Schiavo, 2009). Como señala Gallar (2010), la agricultura urbana cuando es impulsada y fomentada por los movimientos sociales favorece la reticularidad y la proximidad, fortaleciendo las relaciones basadas en la confianza, el apoyo mutuo y la conexión con otros movimientos sociales. Siendo éste un aspecto que se está afianzado en el entramado de los huertos urbanos de Málaga desde el momento en que algunos surgieron tras los movimientos del 11-M y con la creación de asociaciones que se han convertido en las gestoras de los huertos.

La diversidad en la composición social de las personas que se implican en las iniciativas de agricultura urbana resulta uno de sus rasgos distintivos y ha propiciado su diversidad. Las motivaciones e intereses movilizados para implicarse en estas experiencias han sido muy variadas (ecologistas, vecinales, relacionales, nutricionales, ocio), con estilos de vida muy distintos, así como el abanico de edades de sus participantes que oscila entre la juventud y la tercera edad. Ello ha desencadenado una diversidad de tipologías de huertos dependiendo de los barrios o instituciones donde se ubiquen, las composiciones de sus grupos promotores, las facilidades o dificultades en el acceso a recursos.

Desde el punto de vista estrictamente económico, también se ha puesto de manifiesto que es una alternativa rentable desde dos perspectiva, por una parte para la administración, desde el momento que el coste de implantación se amortizaría en una media de 6 años (Fernández, 2013), que podría reducirse con el paso del tiempo si se trabaja de una forma sistemática. Y, por otro lado, desde el punto de vista de los usuarios de los huertos, puesto que potencia la 
sostenibilidad económica ayudando a reducir el presupuesto familiar de la cesta de la compra y generando mayor control sobre la calidad de los alimentos que llegan a la mesa.

Desde el punto de vista medioambiental, ha tenido importantes resultados en cuanto a la mejora del aspecto de los solares abandonados, y en la generación de zonas vegetadas, además a través de las técnicas ecológicas a la hora de sembrar, abonar, regar y recolectar los productos, los huertos están cumpliendo con un compromiso firme de protección del medioambiente. Si bien, este aspecto puede tener implicaciones negativas cuando no se establecen criterios de diseño y ordenación del aspecto visual, de forma que por su aspecto se parezcan más a un "jardín comestible" que a un espacio residual con plantaciones. Realidad que se ha detectado en los entornos de algunos huertos urbanos cuando el espíritu de colectividad no se ha afianzado suficientemente, no existen unas normas claras de funcionamiento y el grupo no participa en las labores colectivas.

Como se ha apreciado a lo largo del trabajo, el movimiento de agricultura urbana se ha asentado en la ciudad de Málaga, prueba de ello es la existencia de 19 solares acondicionados para ello, la participación de más de 1000 hortelanos, así como una amplia tipología que contemplan a una amplia gama de colectivos sociales, sin embargo, aún es un proceso que está en vía de consolidación y requiere una mayor organización e implicación de cara a su fortalecimiento y viabilidad futura.

Uno de los puntos débiles que habría que afrontar es la existencia de una verdadera voluntad política de fomentar este tipo de proyectos. Para ello es necesario que la administración, en sus diferentes niveles, tome conciencia de los importantes beneficios que los huertos proporcionan a las ciudades y a sus usuarios y ponga en marcha políticas y medidas que favorezcan su desarrollo. ${ }^{16}$ En este línea, la voluntad política que fomenta este tipo de proyectos no sólo debe circunscribirse a aportar los recursos materiales y la financiación necesarios para su puesta en marcha, sino también velar por el mantenimiento del proyecto en el tiempo. En este sentido, desde el ámbito de la Universidad de Málaga parece que el futuro de los huertos urbanos está garantizado, prueba de ello es la apuesta decidida desde el Vicerrectorado de Smart-Campus por dar continuidad al proceso iniciado, terminando los proyectos en curso y atendiendo y cubriendo las necesidades de los proyectos en marcha. Desde el Ayuntamiento de la capital la

16 Un ejemplo significativo de estas medidas podría ser el programa municipal "Pla Buits Urbans amb implicació Territorial i Social (Pla BUITS)", impulsado por el Ayuntamiento de Barcelona, con la finalidad de dinamizar e integrar en la ciudad los espacios vacíos 
continuidad de los proyectos depende de la implicación de los colectivos y la presión que desarrolle la población sobre la entidad promotora, desde el momento en que el punto de arranque de los mismos era gestionar el suelo de la ciudad y los huertos urbanos era una más de las actividades que se podían desarrollar.

La existencia actual de 19 huertos urbanos, algunos de ellos aún no consolidados, muestra la insuficiencia para una ciudad de más de 550000 habitantes, además cuando existen aún en los barrios periféricos múltiples solares abandonados con impactos paisajísticos muy negativos y, en las áreas periurbana, muchas parcelas en desusos, abandonadas ante la precaria situación de la agricultura comercial. Haría falta que se impulsara desde el Ayuntamiento, especialmente desde el área de medioambiente, en coordinación con las juntas de distritos municipales y bajo el paraguas de la Agenda 21 y el Pacto de Milán, un plan que fomente los huertos urbanos sociales cuyo elemento central fuera una ordenanza reguladora, así como elaborar un protocolo para la cesión y uso de estos espacios en desuso, degradados y abandonados tanto públicos, como privados. Como indican De Bon et al. (2010) y Fantini (2016), la propuesta de una mayor integración de la agricultura en la planificación urbanística se hace fundamental. En este sentido, es fundamental el reconocimiento normativo de los huertos urbanos en los planos de ordenación del suelo ${ }^{17}$ (Fernández, 2013).

Por último, se requeriría establecer algún organismo de coordinación de los huertos, ${ }^{18}$ de asesoramiento a las asociaciones y a los usuarios, desde el momento en que muchos hortelanos se encuentran con serias dificultades en las prácticas de cultivo y no hallan el asesoramiento técnico necesario, sólo a través de las redes sociales, los hortelanos con mayor experiencia y la junta de distrito. Asimismo, mejorar la comunicación con la Administración es otro requisito ineludible, ya que existen algunos huertos con espacios suficientes para una posible ampliación - la existencia de bancales abandonados (Huertos Moliere, el Caminito) que no han sido reasignados, si bien hay listas de espera para poder ser ocupados.

Son todas medidas que redundarían positivamente en la continuidad futura de los huertos en la ciudad para que estas iniciativas puedan tener una incidencia social considerable y no se queden en dinámicas emergentes que no acaban de despuntar.

17 Hay planes generales, como por ejemplo el de Turín, que imponen una dotación mínima como una de las categorías de zonas verdes, así como el Plan Verde del Cauce del Rio Turia en Valencia (España).

18 En este sentido la red de huertos urbanas creada en Málaga puede constituirse como elemento de referencia para el funcionamiento y desarrollo de los huertos urbanos, transformarse en un organismo que actúe de hecho y no sea una organización puramente testimonial. 
Declaración responsable: Las/os autoras/es declaran que no existe ningún conflicto de interés con relación a la publicación de este artículo. Las/os autoras/es han contribuido con un peso semejante en el trabajo que ha requerido la realización del artículo. Sin embargo hay que apuntar que David Carruana Herrrera se ha implicado especialmente en el trabajo de campo, y Remedios Larrubia Vargas ha desarrollado, además, la función de coordinación del trabajo y los análisis y valoraciones del artículo para su publicación 


\section{Bibliografía}

Aguglia, H., \& Salvioni, C. (2009). Multifunctional agriculture. Napoli: Scientifiche Italiam.

Arosemena, G. (2012). Agricultura urbana. Espacios de cultivo para una ciudad sostenible. Barcelona: Editorial Gustavo Gilli, S.L.

Ayuntamiento de Málaga (2011). Huerto urbano en Carretera de Cádiz. In De un trazo. Retrieved from https://deuntrazo.pro/trabajos/proyectos-anteriores/huerto-urbano-carretera-cadiz/

Baigorri, A., Ballesteros, G, Domingo, E., \& Gaviria, M. (1983). Posibilidades de desarrollo de la Agricultura Periurbana en el Área Metropolitana de Madrid. COPLACO.

Ballesteros, G. (2018). Situación actual de los huertos urbanos en el Estado Español. III Congreso Estatal de huertos ecológicos urbanos y periurbanos (pp. 1-17). Valencia, June 18-19. Retrieved from https://www.agroecologia.net/wp-content/uploads/2018/06/c2-situacion-espanaballesteros-vd.pdf

Busquets i Fábregas, J. (2008) Guia d'integració paisatgística 2. Horts urbans i periurbans. Departament de Política Territorial i Obres Públiques, Direcció General d'Arquitectura i Paisatge, Generalitat de Catalunya. Retrieved from https://docplayer.es/71451386-Guia-d-integraciopaisatgistica-horts-urbans-i-periurbans.html

Cabrera, F., \& Olmedo (2019). M. Cartographica Malacitana. Civitas \& Portus.

Cantor, K. (2010). Agricultura urbana: elementos valorativos sobre su sostenibilidad. Cuadernos de Desarrollo Rural, 7, 61-87. Retrieved from

http://www.scielo.org.co/pdf/cudr/v7n65/v7n65a04.pdf

COAG (Coordinadora de Agricultores y Ganaderos) (2018). Índice de precio en origen y destino de los alimentos. Histórico mes a mes 2008-2019. Retrieved from http://chil.me/downloadfile/104758-281465

Colding, J., \& Bartherl, S. (2013). The potential of urban green commons in the resilience buliding of cities. Ecological Economics, 86, 156-166. Retrieved from https://www.stockholmresilience.org/publications/artiklar/2013-08-26-the-potential-ofurban-green-commons-in-the-resilience-building-of-cities.html

De Bon, H., Parrot, L., \& Moustier, P (2010). Sustainable urban agriculture in developing countries. Agronomy for Sustainable Development, 30, 21-32. 
Dimuro Peter, G., Soler Montiel, M., \& De Manuel Jerez, E (2014). La agricultura urbana en Sevilla: entre el derecho a la ciudad y la agroecología. Hábitat y sociedad, 6, 41-60. Retrieved from https://revistascientificas.us.es/index.php/Hys/article/view/4296

eblancooliva (2016). Málaga según catastro, 2015, por tamaño y fecha. Retrieved from https://eblancooliva.com/2016/12/07/malaga-segun-catastro-a-1-1-2015-por-tamanoyfecha/1900-ch-malaga-1900-plano-de-malaga/

Espinosa Seguí, A., Maćkiewicz B., \& Rosol M. (2017). From leisure to necessity: urban allotments in Alicante province, Spain, in times of crisis. An international Journal for Critical Geographies, 16(2), 276-304.

Fantini, A (2016). Cultivando ciudades. La agricultura urbana y periurbana como práctica de transformación territorial, económica, social y política. Tesis doctoral. Universidad Autónoma de Barcelona. Retrieved from

https://www.educacion.gob.es/teseo/imprimirFicheroTesis.do?idFichero=OcZ6cSfFzeM\%3D

FAO (1996). El Estado Mundial de la Agricultura y la Alimentación. Roma. Retrieved from http://www.fao.org/3/w1358s00.htm

FAO (2013). Agricultura Urbana y Periurbana en América Latina y El Caribe: una realidad. Santiago de Chile: Organización de las Naciones Unidas para la Agricultura y la Alimentación. Retrieved from http://www.fao.org/fileadmin/templates/FCIT/PDF/Brochure_FAO_3.pdf

FAO (2014). Ciudades más verdes en América Latina y el Caribe. Retrieved from http://www.fao.org/ag/agp/greenercities/pdf/GGCLAC/Ciudades-mas-verdes-AmericaLatina-Caribe.pdf

FAO (Comité de Agricultura, COAG) (1999). Agricultura urbana y periurbana. Introducción. Capítulo III y IV. Rome, January 25-29. Retrieved from http://www.fao.org/unfao/bodies/coag/coag15/x0076s.htm

Fernández, N. (2013). Huertos urbanos en Málaga como alternativa sostenible a los solares en desuso. In VII Congreso Aula Greencities (Foro de inteligencia y sostenibilidad urbana (pp. 1-20). Málaga. Retrieved from http://aulagreencities.coamalaga.es/315/

Fleury, A. (2006). Multifuncionalidad y sostenibilidad de la agricultura urbana. Revista de Agricultura Urbana, 15, 4-6. 
Gallar, D., \& Vara, I. (2010). Desagrarización cultural, agricultura urbana y resistencias para la sustentabilidad. Cuadernos Patrimonio Cultura en la nueva realidad andaluza, 59-71. Retrieved from http://www.agriculturaurbana.cat/wp-content/uploads/David-Gallar-e-lsabel-Vara.pdf

García Bujalance, S. (2015). Plan general de Málaga de 1983: Un instrumento para la transformación urbana (Doctoral dissertation, Universidad de Málaga, Spain). Retrieved from https://riuma.uma.es/xmlui/handle/10630/13750

Garzón, E. (2011). Cartilla para el manejo integrado de la fertilización, las plagas y las enfermedades. Bogotá: Jardín José Celestino Mutis, Alcaldía Mayor de Bogotá D.C. Retrieved from https://es.scribd.com/doc/31695652/CARTILLA-TECNICA-AGRICULTURA-URBANALARDIN-BOTANICO

Grupo Nacional de Agricultura Urbana (2001). Lineamientos para los subprogramas de agricultura urbana para el año 2002 y sistema evaluativo. La Habana. Cuba

Hermi Zaar, M. (2011). Agricultura urbana: algunas reflexiones sobre su origen e importancia actual. Biblio 3W. Revista bibliográfica de Geografía y Ciencias Sociales, XVI(944), 119. https://doi.org/10.12795/HabitatySociedad.2013.i7.01

IECA (Instituto de Estadística y Cartografía de Andalucía) (2016). "Andalucía la imagen cartográfica" Málaga. Puerto, industria y turismo [Exhibition]. Junta de Andalucía. Retrieved from https://www.juntadeandalucia.es/institutodeestadisticaycartografia/blog/2016/10/exposi cion-imagen-cartografica-malaga/

Ingersoll, R., Sassatelli, M., \& Fucci, B. (2007). Agricivismo: agricoltura urbana per la riqualificazione del paesaggio. Regione Emilia-Romagna, Italy.

Junta de Andalucía (2015). Estadística y cartografía de Andalucía. Retrieved from http://www.juntadeandalucia.es/institutodeestadisticaycartografia/blog/2015/09/mapasineditos/

Lawson, L. (2004). The planner in the garden: A historical view into the relationship between planning and community gardens. Journal of Planning History, 3. https://doi.org/10.1177/1538513204264752

López Chamizo, S., Sánchez Bandera, P., \& Cumpián Rodríguez, A. (2013). El arrabal de AlTabbanim o de los Mercaderes de la Paja. Málaga. Mainake, 35, 125-143. Retrieved from https://www.researchgate.net/publication/273958483_El_Arrabal_de_Al-

Tabbanim_o_de_los_Mercaderes_de_la_Paja_Malaga 
Losada, H., Martínez, J., Vieyra, R., Pealing R., Zavala, R., \& Cortés, J. (1998). Urban Agriculture in the Metropolitan Zone of Mexico: changes over time in urban, su-urban and peri-urban area. Environmentand Urbanization, 10(2). https://doi.org/10.1177/095624789801000214

Lovell, S.T. (2010). Multifunctional urban agriculture for sustainable land use planning in the United Satates. Sustainability, 2(8), 2499-252. https://doi.org/10.3390/su2082499

Martín Cerdeño, V.J. (2014). Consumo de frutas y hortalizas en España. Distribución y consumo, 4(139), 5-27. Retrieved from

https://www.mercasa.es/media/publicaciones/223/1445187890_DYC_139_100px.pdf

Méndez, M., Ramírez, L., \& Alzate, A. (2005). La práctica de la agricultura urbana como expresión de emergencia de nuevas ruralidades: reflexiones en torno a la evidencia empírica. Cuadernos de desarrollo rural, 5, 51-70. Retrieved from https://www.redalyc.org/articulo.oa?id=11705504

Ministerio de Agricultura pesca y alimentación (2019). Informe del consumo alimentario en $\begin{array}{llll}\text { España } & 2018 . & \text { Madrid. } & 2019\end{array}$ from https://www.mapa.gob.es/es/alimentacion/temas/consumo-y-comercializacion-ydistribucion-alimentaria/20190807_informedeconsumo2018pdf_tcm30-512256.pdf

Moran Alonso, N., \& Hernández Aja, A. (2011). Historia de los huertos urbanos. De los huertos para pobres a los programas de agricultura urbana ecológica. In I Congreso Estatal de Agricultura Ecológica Urbana y Periurbana. Elche, May 6-7. Retrieved from http://oa.upm.es/12201/1/INVE_MEM_2011_96634.pdf

Morán Alonso, N. (2008-2009). Huertos urbanos en tres ciudades europeas: Londres, Berlín, Madrid. Boletín CF+S 47/48. Sobre la (in)sostenibilidad en el urbanismo, 75-124. Retrieved from https://www.researchgate.net/publication/268184632_Huertos_Urbanos_en_tres_ciudad es_europeas_Londres_Berlin_Madrid

Morán Alonso, N. (2010). Agricultura urbana: un aporte a la rehabilitación integral. Papeles de relaciones ecosociales y cambio global, 111, 99-111. Retrieved from http://oa.upm.es/12160/1/INVE_MEM_2010_76416.pdf

Moreno F, O. (2007). Nuevas Estrategias de Integración Social y Recuperación Ambiental en la Ciudad. Diseño Urbano y Paisaje, 11, 1-14. Retrieved from http://dup.ucentral.cl/p df/11_agricultura_urbana.pdf 
Moreno Peralta, S., Quero Castanys, D., \& Seguí Pérez, J. (1989). "La ciudad y el nuevo Plan: Málaga". In Diez años de planeamiento urbanístico en España: 1979-1989 (pp.71-80). Centro de Publicaciones del MOPU.

Mougeot, L. (2001). Agricultura urbana: Definición, presencia, potencialidades y riesgos. Cuaderno Temático, 1, 1-43. Retrieved from https://docplayer.es/17553184-Agricultura-urbanadefinicion-presencia-potencialidades-y-riesgos-luc-j-a-mougeot-7-introduccion.html

Mougeot, L. (2005). Agropolis. The social, political and environmental dimensions of urban agriculture. Earthscan Publications, oxon

Mougeot, L. (2006). Cultivando mejores ciudades. Agricultura urbana para el desarrollo sostenible. Canadá. Centro Internacional de Investigaciones para el Desarrollo. Retrieved from https://docplayer.es/17553184-Agricultura-urbana-definicion-presencia-potencialidades-yriesgos-luc-j-a-mougeot-1-introduccion.html

Moustier, P. (1999). "La complementarité entre agriculture urbaine et agriculture rurale". In Smith (Ed.), Agriculture urbaine en Afrique de l'Ouest: une contribution à la securité alimentaire et á l'assainissement des villes (pp. 41-55). Ottawa, Canada.

Mullins Garcés, I. (2010). Cosechando experiencias en huertos urbanos de Barcelona. El modelo de ficha urbe-hortícola como recurso de comunicación socio-ambiental. Tomo I. Barcelona. Retrieved from https://huertosurbanosbarcelona.files.wordpress.com/2010/08/tomo_i_sinanexos.pdf

Muñoz Martín, M. (2006). Familias malagueñas del S. XIX para recordar. Málaga: Málaga Editores.

Muñoz, L. (2104). Siete tipos de huertos urbanos: sus objetivos y beneficios. Agrohuertos. Retrieved from https://www.agrohuerto.com/7-tipos-de-huertos-urbanos/

Nahmias, P., \& Le Caro, Y. (2012). Pour une definition de l'agriculture urbaine: réciprocité fonctionnelle et diversité des formes spatiales. Environment urbain, 6, 1-16.

OMAU (Observatorio de medio urbano de Málaga) (2016a). Territorio y configuración de la ciudad. Retrieved from http://static.omau-malaga.com/omau/subidas/archivos/6/2/7726/agenda-urbana-malagaindicadores-de-sostenibilidad-2016-01-territorio_v2.pdf 
OMAU (Observatorio del medio urbano de Málaga) (2016b). Cohesión social y desarrollo económico. Málaga: Ayuntamiento de Málaga, Área de sostenibilidad medioambiental. OCDE (Organización para la Cooperación y el Desarrollo Económico) (1979). Agricultura Periurbana. Paris.

Partalidou, M., \& Anthopoulou, T. (2017). Urban allometnt gardens during precariuous times: from motives to lived experiences. Sociologia Ruralis, 57(2), 21128. https://doi.org/10.1111/soru. 12117

Pérez Lara, J., Matas, A.J., \& Quesada. M.A. (2016). Huertos urbanos en el municipio de Málaga. In Las leguminosas claves en la gestión de los agrosistemas y en la alimentación ecológica (pp.1-16). In Actas del XII Congreso de la Sociedad Española de Agricultura Ecológica. Lugo, September 21-23. Retrieved from

https://riuma.uma.es/xmlui/bitstream/handle/10630/13624/HuertosUrbanosenelMunicipio_d eMálaga_FinSeg16.pdf? sequence=3\&isAllowed =y

PGOU (Plan General de Ordenación Urbana de Málaga) (2011). Capítulo II. Planeamiento urbano. Evolución histórica. Aprobación provisional, junio, 2010. Ayuntamiento de Málaga. Retrieved from

http://www.malaga.eu/recursos/urbanismo/PGOU_WEB/aprobinicial_2006/memoria/M.\%2 OINFORMATIVA.\%20TITULO\%20III\%20Capitulo\%20II.pdf

Puente Asuero, R. (2012) Los huertos urbanos de Sevilla: de la tradición a la novedad. Sevilla: Diputación de Sevilla.

Soler Montiel, M., \& Renting, H. (2014). La agricultura urbana en la planificación de las ciudades: entre la participación y el mercado. Hábitat y sociedad, 7, 511. https://doi.org/10.12795/HabitatySociedad.2013.i7.01

Schiavo, C. (2009). Empoderamiento y acción colectiva en producciones agroalimentarias con identidad territorial. Pampa, 5, 9-50

Torres Lima, P. (2000). Sustentabilidad y agricultura urbana. In P. Torres Lima (Coord.), Procesos metropolitanos y agricultura urbana. México: Universidad Autónoma Metropolitana-Xochimilco.

Universidad de Málaga (2019). Presupuesto 2019 de la Universidad de Málaga. Retrieved from https://www.uma.es/media/files/Presupuesto_2019.pdf 
Valle Buenestado, B. (1978). Los huertos familiares de la provincia de Córdoba. Notas para el estudio de las obras realizadas por el Instituto Nacional de Colonización. Cuadernos de Geografía de la Universidad de Granada, 8, 295-270.

Villace, B., Labajos, L., Aceituno-Mata, L., Morales, R., \& Pardo de Santayana, M. (2014). La naturaleza cercana. Huertos urbanos colectivos madrileños. Ambienta, 107, 54-73. Retrieved from

https://www.ucm.es/data/cont/media/www/pag-

56050/Ambienta\%20n\%C2\%BA\%20107\%20|unio\%202014.\%20La\%20naturaleza\%20cercana. \%20Huertos\%2Ourbanos\%20colectivos\%20madrile\%C3\%B1os.\%20Villace\%20et\%20al..pdf

Yacamán Ochoa, C. (2018). Agricultura periurbana: revisión crítica de los riesgos y desafíos en la actual agenta política de las interacciones agro-urbanas. Biblio 3W, Geocrítica, XXIII, 1237. Retrieved from https://revistes.ub.edu/index.php/b3w/article/view/26487/27879 


\section{Anexo I. Guión entrevista huertos urbanos}

\section{CONSTITUCIÓN Y GESTIÓN DE LOS HUERTOS URBANOS}

1.1. ¿Cuándo surge el huerto urbano?

1.2 ¿Quiénes y porqué tomaron la decisión de constituir un huerto urbano? Un poco de historia

1.3 ¿Cuáles fueron las principales causas o factores que motivaron la realización y el desarrollo del huerto urbano? (Necesidad económica, ocio, terapéutica, medioambiental, formativa/investigación, otras).

1.4. ¿Qué actuaciones se llevaron a cabo para poner en funcionamiento el huerto y quienes fueron los que se encargaron de su acondicionamiento?

1.5. ¿A quién pertenecía los terrenos del huerto? ¿Cómo accedieron a ellos? ¿En qué situación se encuentran en la actualidad?

1.6. ¿Quién es su promotor y/o gestor? ¿Está adscrito el huerto a alguna Asociación?

\section{PERFIL SOCIAL DE LOS USUARIOS}

2.1. ¿Cuántos usuarios hay en el huerto?

2.2. ¿De dónde proceden los usuarios de los huertos?

2.3. ¿Qué edades tienen los usuarios?

2.4. ¿Qué nivel formativo poseen? (Sin estudios, Estudios básicos, Estudios medios, Estudios superiores).

2.5. ¿Cuál es la situación laboral de los usuarios? : Ocupado, ¿en este caso cuál es su actividad?, parado, jubilado.

2.6. ¿Cuál es el sexo de los usuarios de los huertos?

2.7. ¿Cuántas personas forman parte de su núcleo familiar?

2.8. ¿Cuál es la procedencia de la renta de los usuarios?

2.9. ¿Qué supone el huerto en la economía familiar? (Nada, una ayuda, cubre el consumo en hortícola, otros).

2.9 ¿Tenían los usuarios conocimientos previos sobre agricultura?

- En caso negativo: ¿Cómo han adquirido los conocimientos actuales?

- En caso afirmativo. ¿Han aumentado los conocimientos iniciales? 
2.10 ¿Cómo conocieron los usuarios el huerto donde participan?

2.10 ¿Crees que los conocimientos que poseen los usuarios son suficientes para el manejo del huerto?

\section{CARACTERÍSTICAS Y FUNCIONAMIENTO DEL HUERTO}

3.1. Localización: calle, distrito, barrio.

3.2. ¿Cuál es la extensión de la parcela del huerto urbano?

3.3. ¿Cuál es el número de parcela en la que se dividen el huerto?

3.4. ¿Cuál es el tamaño de las parcelas?

3.5. ¿Cuál es el proceso de adjudicación de las parcelas?

3.6. ¿Cuánto es el tiempo de disfrute de las parcelas por los usuarios?

3.7. ¿Cuál es la cuota a pagar por el disfrute de las parcelas del huerto?

3.8. ¿Existe ordenanza o reglamento para el funcionamiento del huerto?

- En caso negativo ¿Qué normas internas se siguen?

3.9. ¿Cuáles son los requisitos exigidos a los usuarios para acceder a una parcela?

3.10. Indique cuál es la infraestructura existente en el huerto: Accesos/caminos, Red de riego, Tipo de riego, Instalación eléctrica, Cerramiento/tipo, Casetas/edificios, Semilleros, Composteras, Otros equipamientos (zona de ocio, infantil, etc.).

\section{MANEJO DEL HUERTO}

4.1. ¿Cuáles son los productos que se cultivan?

4.2. ¿De dónde procede las plantas o semillas?

4.3. ¿Por qué se cultivan esos productos y no otros?

4.4. ¿Cambia de productos cada temporada? ¿Por qué?

4.5 ¿Cuántas cosechas se extraen por año?

4.6. ¿Cuánto tiempo se invierte por día/por semana, etc. en el huerto según temporada?

4.7. Indique cuáles son las labores de cultivos anuales (tipo, número, cantidad de producto, etc.).

4.8. Indique por producto el gasto aproximado. 
4.9 Indique la productividad por producto y $\mathrm{m}^{2}$. ¿Cómo ha evolucionado la productividad?

4.10 ¿Cuál es el destino de los productos del huerto?

4.1i. ¿Qué destino tiene los residuos?

4.12 ¿Cuál es la maquinaria que se usa para las labores de cultivo?

4.13 ¿Con qué personal se cuenta para realizar las labores de cultivo?

4.14. ¿Cuál es el régimen de tenencia de las parcelas del huerto?

4.15. ¿Qué método de trabajo se sigue para conseguir un orden a la hora de cultivar y organizarse con los demás participantes?

4.16. ¿Qué problemas internos o externos existen a la hora de cultivar el huerto?

4.19 ¿Hay reuniones entre los miembros que participan en el huerto? ¿Cuántas? ¿Cuál es su utilidad?

4.20. ¿Cómo conoció el huerto los participantes?

4.21 ¿Qué beneficios ha aportado individualmente y colectivamente (al barrio o la ciudad) el cultivo del huerto?

4.22 ¿Cómo ve la proyección futura del huerto? (Continuidad, ampliación, remodelación, otros) 
Anexo II. Localización de los distintos huertos urbanos en la ciudad de Málaga

\begin{tabular}{|c|c|c|c|c|c|c|c|}
\hline $\begin{array}{l}\text { Nombre de los } \\
\text { huertos }\end{array}$ & Distrito & Propiedad & $\begin{array}{l}\text { Ubicación } \\
\text { respecto a la } \\
\text { ciudad }\end{array}$ & Nombre de los huertos & Distrito & Propiedad & $\begin{array}{l}\text { Ubicación } \\
\text { respecto a } \\
\text { la ciudad }\end{array}$ \\
\hline 1. El Caminito & Centro & $\begin{array}{l}\text { Pública- } \\
\text { Municipal }\end{array}$ & Intraurbana & 11. Püro Huerto & Campanillas & Privada & Periurbana \\
\hline 2. Moliere & $\begin{array}{l}\text { Carretera } \\
\text { Cádiz } \\
\end{array}$ & $\begin{array}{l}\text { Pública- } \\
\text { Municipal }\end{array}$ & Intraurbana & 12. Llano Oliveros & Campanillas & Privada & Periurbana \\
\hline $\begin{array}{l}\text { 3. Vergel de } \\
\text { Málaga }\end{array}$ & $\begin{array}{l}\text { Palma- } \\
\text { Palmilla }\end{array}$ & $\begin{array}{l}\text { Pública- } \\
\text { Municipal }\end{array}$ & Intraurbana & 13. La Píndola & $\begin{array}{c}\text { Puerto de la } \\
\text { Torre }\end{array}$ & $\begin{array}{l}\text { Pública- } \\
\text { Municipal }\end{array}$ & Periférica \\
\hline $\begin{array}{l}\text { 4. Huerta } \\
\text { Dignidad }\end{array}$ & $\begin{array}{l}\text { Palma- } \\
\text { Palmilla }\end{array}$ & $\begin{array}{l}\text { Pública- } \\
\text { Municipal }\end{array}$ & Intraurbana & $\begin{array}{c}\text { 14. Centro Scout } \\
\text { medioambiental. Vallejera }\end{array}$ & $\begin{array}{l}\text { Puerto de la } \\
\text { Torre }\end{array}$ & Privada & Periférica \\
\hline 5. La Yuca & Centro & $\begin{array}{c}\text { Pública- } \\
\text { Universidad }\end{array}$ & Intraurbana & 15. Huerta Urbana & Teatinos & $\begin{array}{l}\text { Público- } \\
\text { Municipal }\end{array}$ & Periférica \\
\hline $\begin{array}{l}\text { 6. Puerta de } \\
\text { Málaga }\end{array}$ & $\begin{array}{l}\text { Carretera } \\
\text { Cádiz }\end{array}$ & $\begin{array}{l}\text { Pública- } \\
\text { Municipal }\end{array}$ & Intraurbana & 16. Aulas abiertas & Teatinos & $\begin{array}{l}\text { Público- } \\
\text { Universidad }\end{array}$ & Periférica \\
\hline 7. La Noria & $\begin{array}{l}\text { Palma- } \\
\text { Palmilla }\end{array}$ & $\begin{array}{c}\text { Pública- } \\
\text { Diputación }\end{array}$ & Intraurbana & $\begin{array}{l}\text { 17. Huerto Docente. } \\
\text { Facultad de Ciencias }\end{array}$ & Teatinos & $\begin{array}{c}\text { Público- } \\
\text { Universidad }\end{array}$ & Periférica \\
\hline $\begin{array}{l}\text { 8. Jardín de } \\
\text { Bailen }\end{array}$ & $\begin{array}{l}\text { Bailén- } \\
\text { Miraflores }\end{array}$ & $\begin{array}{l}\text { Pública- } \\
\text { Municipal }\end{array}$ & Intraurbana & $\begin{array}{l}\text { 18. Huerto Urbano y } \\
\text { parque frutal de la UMA }\end{array}$ & Teatinos & $\begin{array}{l}\text { Público- } \\
\text { Universidad }\end{array}$ & Periférica \\
\hline 9. Huerta Tunesia & Este & Privada & Intraurbana & $\begin{array}{l}\text { 19. Huerto Sensorial } \\
\text { Esperanza }\end{array}$ & Palma-Palmilla & $\begin{array}{l}\text { Público- } \\
\text { Diputación }\end{array}$ & Periférica \\
\hline
\end{tabular}

Fuente: elaboración propia 